\title{
Solar influence on global and regional climates
}

Article

Published Version

open access paper

Lockwood, M. (2012) Solar influence on global and regional climates. Surveys in Geophysics, 33 (3-4). pp. 503-534. ISSN 1573-0956 doi: https://doi.org/10.1007/s10712-012-9181-3 Available at https://centaur.reading.ac.uk/28365/

It is advisable to refer to the publisher's version if you intend to cite from the work. See Guidance on citing.

Published version at: http://dx.doi.org/10.1007/s10712-012-9181-3

To link to this article DOI: http://dx.doi.org/10.1007/s10712-012-9181-3

Publisher: Springer

All outputs in CentAUR are protected by Intellectual Property Rights law, including copyright law. Copyright and IPR is retained by the creators or other copyright holders. Terms and conditions for use of this material are defined in the End User Agreement.

\section{www.reading.ac.uk/centaur}

\section{CentAUR}

Central Archive at the University of Reading

Reading's research outputs online 


\section{Solar Influence on Global and Regional Climates}

\section{Mike Lockwood}

\section{Surveys in Geophysics}

An International Review Journal

Covering the Entire Field of Geosciences and Related Areas

ISSN 0169-3298

Surv Geophys

DOI 10.1007/s10712-012-9181-3

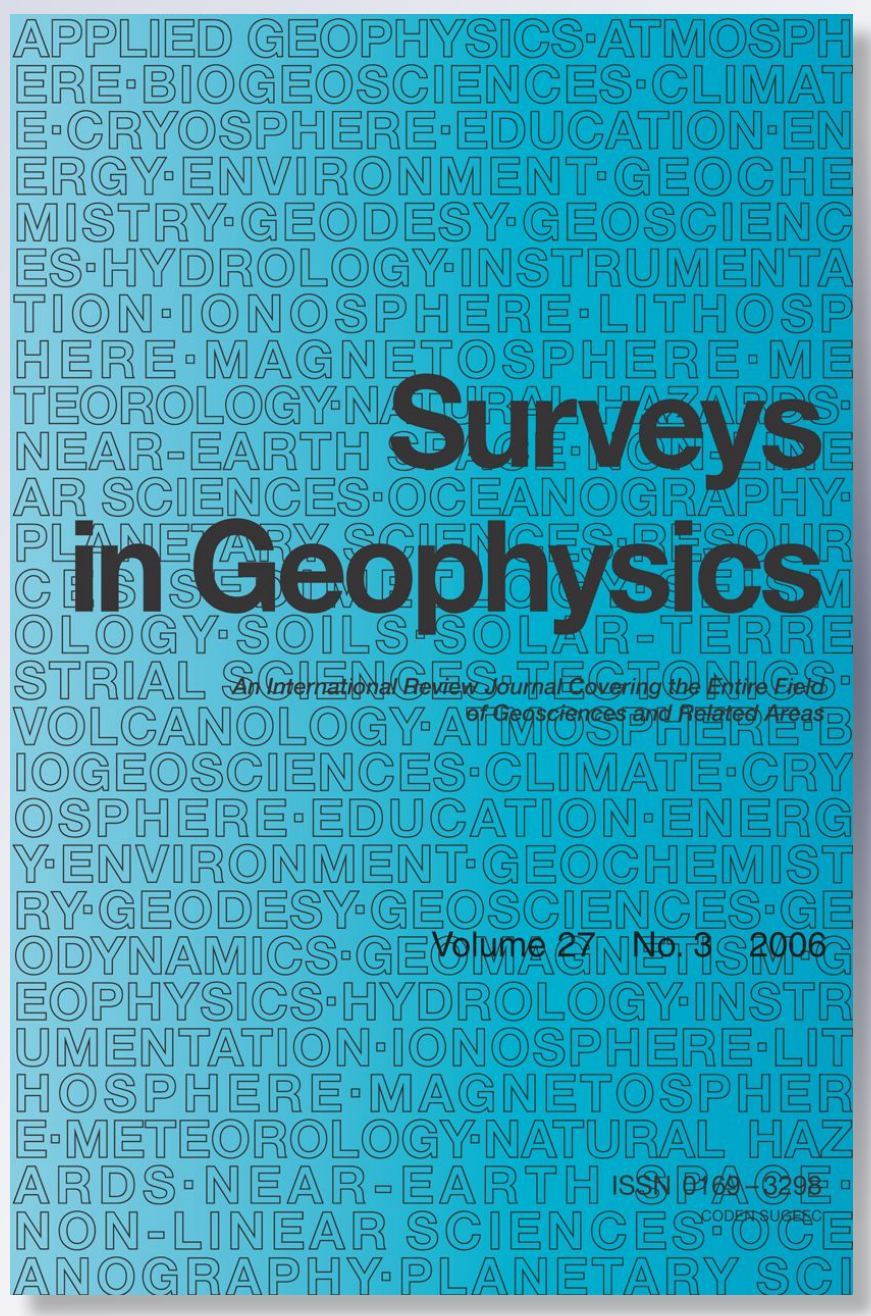

Springer 
Your article is published under the Creative Commons Attribution license which allows users to read, copy, distribute and make derivative works, as long as the author of the original work is cited. You may selfarchive this article on your own website, an institutional repository or funder's repository and make it publicly available immediately. 


\title{
Solar Influence on Global and Regional Climates
}

\author{
Mike Lockwood
}

Received: 5 October 2011 / Accepted: 1 February 2012

(C) The Author(s) 2012. This article is published with open access at Springerlink.com

\begin{abstract}
The literature relevant to how solar variability influences climate is vast-but much has been based on inadequate statistics and non-robust procedures. The common pitfalls are outlined in this review. The best estimates of the solar influence on the global mean air surface temperature show relatively small effects, compared with the response to anthropogenic changes (and broadly in line with their respective radiative forcings). However, the situation is more interesting when one looks at regional and season variations around the global means. In particular, recent research indicates that winters in Eurasia may have some dependence on the Sun, with more cold winters occurring when the solar activity is low. Advances in modelling "top-down" mechanisms, whereby stratospheric changes influence the underlying troposphere, offer promising explanations of the observed phenomena. In contrast, the suggested modulation of low-altitude clouds by galactic cosmic rays provides an increasingly inadequate explanation of observations.
\end{abstract}

Keywords Solar variability - Global climate change $\cdot$ Regional climate change Blocking events - Maunder minimum · Total solar irradiance · UV spectral irradiance . Galactic cosmic rays $\cdot$ Open solar flux $\cdot$ Stratosphere-troposphere coupling

\section{Introduction}

Solar electromagnetic radiation powers Earth's climate system and, consequently, it is often naïvely thought that changes in this solar output must be responsible for changes in Earth's climate. However, the huge thermal time constant of the outer part of the Sun limits the variability in its surface temperature, and hence its total power output, which is

M. Lockwood ( $₫)$

Department of Meteorology, University of Reading, P.O. Box 243, Earley Gate RG6 6BB, UK e-mail: m.lockwood@reading.ac.uk

M. Lockwood

RAL Space, Rutherford Appleton Laboratory, Harwell Campus, Chilton, Didcot, Oxfordshire OX11 0QX, UK 
dominated by visible and infrared emissions from the solar surface (the photosphere) (see review by Lockwood 2004). As a result, changes in solar power output on decadal, centennial and millennial timescales are limited to small changes in effective surface temperature (associated with magnetic fields) and potential, although as yet undetected, solar radius variations (see reviews by Solanki et al. 2005; Lockwood 2010). Larger percentage variations are seen in solar UV emissions (Lean et al. 1997) which arise from the lower solar atmosphere (the chromosphere) (Loukitcheva et al. 2009) and which influence the stratosphere in Earth's middle atmosphere between about 10 and $50 \mathrm{~km}$ (see review by Gray et al. 2010). Even more variable are solar X-rays and extreme ultraviolet (EUV) emissions that originate in the upper solar atmosphere (the corona) and dominate the behaviour of Earth's uppermost atmosphere (the thermosphere, above about 90-km altitude) (Le et al. 2011). In addition to these electromagnetic outputs, the Sun modulates energetic charged particle fluxes incident upon the Earth. Solar energetic particles (SEP) are emitted by solar flares and from the shock fronts that form ahead of super-sonic (and super-Alfvénic) ejections of material from the corona (Schwenn 2006). SEPs are incident upon Earth's atmosphere in polar regions where they enhance the destruction of stratospheric ozone (Jackman et al. 2006; 2008). Even more energetic are galactic cosmic rays (GCRs). These particles are not generated by the Sun; rather, they originate at the shock fronts emanating from violent galactic events such as supernovae explosions. However, the expansion of the shielding solar magnetic field into interplanetary space results in the Sun modulating the number of GCRs reaching Earth (see, for example, review by Potgieter 2008). Air ions generated by GCRs enable Earth's global electric (thunderstorm) circuit (Rycroft et al. 2008), and it has been proposed that they also modulate the formation of low-altitude clouds (Svensmark and Friis-Christensen 1997). The Sun also emits a continuous stream of low-energy charged particles called the solar wind (e.g., Marsch 2006). A small fraction of the solar wind energy incident on Earth is extracted by the geomagnetic field and deposited in the thermosphere at high latitudes (Cowley 1991; Thayer and Semeter 2004). This deposition changes the behaviour of the thermosphere globally (e.g., Fuller-Rowell et al. 2007), but this is an extremely low-density atmospheric layer, and there are no robust observations, nor any confirmed theory, that suggests these thermospheric variations are transmitted through the middle atmosphere to the troposphere below.

Both electromagnetic and charged particle emissions from the Sun are known to vary over the decadal-scale solar magnetic activity cycle, as do GCR fluxes (see review by Lockwood 2004). But any effects on climate are much more significant for any variations over longer timescales. This review discusses and evaluates potential effects on Earth's climate of variations in these solar emissions. "Top-down" mechanisms involve solar UV irradiance (or perhaps energetic particles) modulating stratospheric temperatures and winds which, in turn, may influence the underlying troposphere where Earth's climate and weather reside. These contrast with "bottom-up" effects in which the total solar irradiance (TSI, dominated by the visible and near-IR) variations cause surface temperature changes and upward coupling to the troposphere.

\section{Historical Perspective}

It is interesting to ponder what the author citation h-index of the astronomer Sir Frederick William Herschel (1738-1822) would be. Certainly, his 1801 paper (Herschel 1801), in which he speculated on a connection between sunspots and regional climate (for which he used the market price of wheat as a quantifiable proxy), has been cited a great many times 
and continues to be cited regularly today. Herschel appears to have been more aware of the limitations of his apparent correlation (writing "this prediction ought not to be relied on by anyone") than many who have subsequently cited his paper. Indeed, Herschel himself notes limitations to his speculation that many subsequent studies of solar influence on climate have failed to adequately consider. Common pitfalls include the following:

1. The potential for selection effects mean that one must ask, "Would a reported correlation coefficient be as high if an equivalent data set were substituted?" (For example, in Herschel's case, was the behaviour of the price of barley similar to that of wheat? If not, why not?) Selection effects can often arise (unintentionally or otherwise) from the use of restricted data intervals and/or the choice of which parameters to compare. Selection effects are the major reason why the specific issues (2)-(5) below are particular problems.

2. Sunspots are only indirectly related to the solar outputs that are relevant to climate. (Herschel attempts to build an argument about enhanced emission from sunspots which we now know to be incorrect).

3. The lack of suitable measurements of Earth's global climate on long timescales leads to the use of indirect proxies (Herschel used the price of wheat), and there are many other factors, unrelated to climate, which can influence such proxies.

4. The climate data used have often been for a limited season (in Herschel's case, this is effectively the growing season of wheat) which may not adequately reflect changes in the annual mean data.

5. The climate data used have often been regional, and not global (Herschel used the price of wheat in the UK and not on the global market); regional climates show large variations around the global mean.

6. The data sets are not homogeneous, and measurement series often contain instrumental drifts and discrete jumps. (Herschel notes this in respect of the sunspot data available to him).

7. Correlations can occur by chance, and the probability of this happening must be evaluated, allowing for the persistence in the data time series and the number of free parameters. Hence, the significance of any correlation must be determined (by comparison with a suitable noise model). In addition, tests are needed to prevent "data snooping", that is, exploiting a feature in the data that turns out to be a statistical or instrumental artefact. To ensure that wrong conclusions are not drawn from statistical coincidences, clear null hypotheses must be formulated and proper statistical tests performed (Yiou et al. 2010; Legras et al. 2010; Love et al. 2011).

8. Solar variability effects are convolved with other influences on climate (volcanoes, aerosols, land-use changes and greenhouse gases). For example, Herschel neglected the effects of volcanic eruptions that occurred during the interval that he studied.

9. The effects of internal climate variability have often been overlooked or underestimated. There are internal oscillations (particularly associated with the oceans on decadal timescales), and a common error is to "overfit" the data, thereby wrongly ascribing variations to an external solar origin. There are a huge number of publications looking at oscillations at periods close to that of the solar cycle and/or correlations with the solar cycle at a fixed lag. Tests of some of these reveal that they are unlikely to be driven by solar forcing and that they are more likely to reflect other natural cycles of the climate system or a harmonic combination of various multiyear cycles (Drijfhout et al. 1999; Moore et al. 2006). 
10. Even a statistically significant correlation or detected periodic signal does not establish causality, neither do lags nor phase relationships for coupled systems involving stationary oscillations.

11. Lastly one must ask, "Is there a realistic mechanism or series of mechanisms that could have given rise to the correlation?" (Herschel's proposal invoked a chain of interactions, encompassing solar physics, climate science, agricultural science and the effect of supply-and-demand in economics!).

The reason why the citation rate for Herschel's speculation is so high is that a great many subsequent studies have explored the same ideas. The growth in modern-day interest can be traced to John A. “Jack” Eddy (1931-2009). Incidentally, Eddy's h-index is known and is modest, by modern standards, at 14; however, his most influential paper (Eddy 1976) has been cited 954 times (citation analysis using Web of Science, October 2011). This famous paper particularly focussed on European temperature records and the period of extremely low solar activity (when almost no sunspots were observed) known as the Maunder Minimum (circa 1645-1715). This topic is discussed further in Sect. 6 of the present review.

The academic reputation of the field of Sun-climate relations is poor because many studies do not address all, or even some of, the limitations listed above. It is also a field that in recent years has been corrupted by unwelcome political and financial influence as climate change sceptics have seized upon putative solar effects as an excuse for inaction on anthropogenic warming. In particular, figures and statistics with known errors, limitations and inaccuracies are repeatedly reproduced on the Internet and in the media (as discussed, for example, by Damon and Laut 2004), and publications are reported in a massively selective manner. None of this makes any difference to the scientific reality, or otherwise, of mechanisms connecting solar variability and Earth's climate; however, it does make evaluation of the evidence much more difficult. Recent reviews have been presented by Reid (2000), Rind (2002), Haigh (2003, 2007), Beer (2006), Foukal et al. (2006), de Jager (2008), Gray et al. (2010) and Lockwood (2004, 2010, 2012).

\section{Solar Variability and Global Climate Response Timescales}

Solar outputs reaching Earth undergo periodic variations over a range of timescales. These include the 27-day variation due to solar rotation, annual variations due to the ellipticity of Earth's orbit, the decadal-scale solar magnetic (sunspot) cycle and oscillations between grand solar maxima and minima on timescales of several centuries. How a key climate parameter, such as the Global Mean Air Surface Temperature (GMAST), varies in response to these solar variations will depend on its response timescale. Estimates of the GMAST response time have varied from less than 1 year to several decades and, in reality, the role of the oceans means that a spectrum of response times is to be expected. Knutti et al. (2008) discuss the time constants of different parts of the climate system: short time scales (1 year or less) apply to atmospheric adjustments and land surface processes; medium time scales (of order decades) to the melting of sea ice; and long time scales (many decades) to warming of the whole ocean surface layer. Ocean warming effects are complex because of mixing behaviour (Hansen et al. 1985), but an effective timescale of 5-20 years has been predicted by Dickinson and Schaudt (1998). The climate response modelling of Rind et al. (1999) and analysis of pre-industrial data by Waple et al. (2002) and Weber (2005) yield response times of up to 10 years. Held et al. (2010) use both an 
energy balance model (EBM) and a coupled atmosphere-ocean General Circulation Model (GCM) to investigate the implications of two time constants-a rapid response on a timescale of about 5 years and a slower "recalcitrant" response on a timescale of several hundred years. They show that the rapid response is currently dominant, but the longer timescale would become important if greenhouse gas emissions were to be stabilised. All these time constants mean that responses to 27-day solar variations will be damped to undetectable levels in GMAST, whereas the centennial solar variations should be reflected almost in full. The extent to which the solar-cycle variations are damped is still a matter of debate. Some studies find that the GMAST response to recent solar cycles may be $0.1 \mathrm{~K}$ or larger (White et al. 1997; Douglass and Clader 2002; Camp and Tung 2007; Lean and Rind 2009). However, some of the apparent responses found in regression studies of empirical data may not, in reality, be due to real associations and causality. This is because of one or more of the potential pitfalls discussed in Sect. 1 (such as overfitting so that internal variability is ascribed to external forcing, degeneracy between different forcing factors, understated uncertainties in regression coefficients and in the response to forcing). That this can be the case has been demonstrated clearly using model simulations (Ingram 2006; Benestad and Schmidt 2009; Stott and Jones 2009).

\section{Global Climate Response}

This section considers the multidecadal trends (e.g., Brönnimann et al. 2007) rather than the great many reports of putative solar-cycle variations observed in the troposphere (e.g., Camp and Tung 2007; Coughlin 2004; Gleisner et al. 2005). One reason why the global climate response timescales have recently become a consideration is the realisation that, since 1985, all the relevant solar outputs have been changing in the opposite direction to those needed to explain the rise in GMAST (Lockwood and Fröhlich 2007). Thus, for solar activity to contribute to recent warming, there must be a long GMAST response time constant. For example, Scafetta and West (2007) and Scafetta (2009) have employed multiregression fits of GMAST data that involve a short-timescale response (to allow the observed weak solar-cycle variations to be reproduced) plus a long-time-constant response. This is different from the Held et al. (2010) study discussed in the last section because the longer time-constant response dominates. Multiple regression analysis of this kind has been used several times previously (e.g., Santer et al. 2001; Lean 2006; Lockwood 2008), but can be misleading if inter-correlations exist between the data series that are input into the study or if genuine factors are omitted. In addition, naïve regression analyses may also be misleading due to convoluted nonlinear response associated with feedback processes, the use of non-optimal regression techniques or the presence of internal system variability (Benestad and Schmidt 2009). In general, all forcings need to be considered for the attribution of climate change and the effects of degeneracy between solar and volcanic forcings over recent centuries are a particular concern because major eruptions tend to occur at an average rate near one per solar cycle and even have a periodicity close to the 88 years of the solar Gliessberg cycle (Qu et al. 2011) and because bursts of volcanic eruptions and a lack of eruptions can cause long-term cooling and warming, respectively. Hence, such analyses need to be interpreted with a great deal of caution and judgement with regard to the choice of input variables and as to whether the conclusions are sensible. There are other potential pitfalls. For example, there is a strong possibility that the fits of Scafetta and West (2007) and Scafetta (2009) suffer from a "data snooping" problem as they are strongly dependent on a feature in the TSI data composite that they employed 
which has been argued to be a calibration error (Lockwood and Fröhlich 2008). Benestad and Schmidt (2009) present a full critique of the robustness of the fits; however, here, we simply look whether their implications are sensible or not. Scafetta and West (2007) and Scafetta (2009) find that solar change contributed over $60 \%$ of the temperature rise (i.e. more than $0.5^{\circ} \mathrm{C}$ ) since pre-industrial times, and it is instructive to ask, "How does this agree with the changes in the various radiative forcings?"

Our best estimates of $\Delta \mathrm{S}$, the change in the average TSI between the Maunder Minimum and recent decades, have decreased over recent years (see review by Gray et al. 2010). Initially, $\Delta S$ was estimated from surveys of "Sun-like" stars (Baliunas and Jastrow 1990; Zhang et al. 1994), but results of more extensive surveys did not confirm the key result, nor did they support its application to our Sun (Hall and Lockwood 2004; Giampapa 2004). Subsequently, smaller $\Delta \mathrm{S}$ estimates have been derived using sunspot numbers and the open magnetic flux of the Sun, which can be derived from historic geomagnetic data (see review by Lockwood 2004). These studies find $\Delta \mathrm{S}$ to be comparable to the amplitude of recent solar cycles (i.e. 0.1\%) (see Gray et al. 2010 and references therein) and such estimates are currently employed, for example, in the 2007 IPCC report. The more recent estimates of the change in TSI equate to a change in radiative forcing of $\Delta f_{\mathrm{S}}=\Delta S(1-A) /$ 4. Earth's albedo, $A$, is particularly poorly known (Charlson et al. 2005; Pallé et al. 2009) but using a best estimate of $A \approx 0.3$ (Loeb et al. 2009) gives $\Delta f_{\mathrm{S}} \approx 0.24 \mathrm{~W} \mathrm{~m}^{-2}$. Two recent papers disagree with this consensus value, but do not agree on even the sign of the adjustment needed. Schrijver et al. (2011) argue that the consensus $\Delta f_{\mathrm{S}}$ is overestimated, whereas Shapiro et al. (2011) suggest it should be increased by a factor of at least 4 , to a value near $1 \mathrm{~W} \mathrm{~m}^{-2}$. Where these two papers differ is in their treatment of the "quiet" Sun between groups of sunspots ("active regions"), and Lockwood (2011b) argues that neither makes a compelling case for an adjustment to the consensus value at the present time.

From flask measurements and ice-core data, we can compute the radiative forcing caused by the observed rises in well-mixed trace (i.e. excluding water vapour) greenhouse gas (GHG) abundances over the same interval (Forster et al. 2007). The abundance of carbon dioxide has risen from $280 \mathrm{ppmv}$ in pre-industrial times to $362.5 \mathrm{ppmv}$ in 2000 , which corresponds to $+1.56 \mathrm{~W} \mathrm{~m}^{-2}$. The corresponding radiative forcing contributions for other trace GHG are the following: $+0.47 \mathrm{~W} \mathrm{~m}^{-2}$ for $\mathrm{CH}_{4},+0.28 \mathrm{~W} \mathrm{~m}^{-2}$ for $\mathrm{CFCs}$ / $\mathrm{HCFs}$ /halons, and $+0.14 \mathrm{~W} \mathrm{~m}^{-2}$ for $\mathrm{NO}_{\mathrm{x}}$. This gives a total radiative forcing by trace GHG of $\Delta f_{\mathrm{G}}=2.45 \mathrm{~W} \mathrm{~m}^{-2}$, which is ten times larger than our best estimate of the solar forcing $\Delta f_{\mathrm{S}}$. Note that this estimate of $\Delta f_{\mathrm{G}}$ is known with considerable certainty from the analysis of absorption spectra. Persistent reports, mainly in the media and on the Internet, that absorption lines are saturated (such that adding more GHG does not cause any radiative forcing change) ignore a huge body of research that extends back to the 1950s and are demonstrably false when one considers the whole IR spectrum (Shine et al. 1995). Energy balance shows that, for steady state, the observed GMAST rise since the Maunder Minimum would correspond to a total forcing, including feedbacks (which include water vapour effects), of $\Delta f=5.15 \mathrm{~W} \mathrm{~m}^{-2}$ (Lockwood 2010). The uncertainty on this estimate is of order $\pm 0.5 \mathrm{~W} \mathrm{~m}^{-2}$, dominated by the uncertainty in the pre-industrial temperature, with a small contribution from the uncertainty in the power stored in the deep oceans.

Thus, to explain the warming with GHG forcing alone requires feedbacks to account for a forcing of $\Delta f-\Delta f_{\mathrm{G}} \approx 2.67 \mathrm{~W} \mathrm{~m}{ }^{-2}$, that is, a (positive) feedback factor of $a_{\mathrm{G}}=\Delta f$ ) $\Delta f_{\mathrm{G}} \approx 2.1$. To explain $60 \%$ of the warming with solar forcing requires a feedback factor of $a_{\mathrm{S}}=0.6 \times \Delta f / \Delta f_{\mathrm{S}} \approx 12.8$ and a feedback factor of $a_{\mathrm{G}}=0.4 \times \Delta f / \Delta f_{\mathrm{G}} \approx 0.8$ for greenhouse gases. In other words, the fit of Scafetta (2009) requires a huge positive 
feedback for the solar forcing but a negative feedback for the greenhouse forcing. Thus, this fit raises much bigger problems than it solves and makes no sense physically.

But not all multiple regression fits suffer from such problems. Figures 1 and 2 show the results of a fit to recent GMAST data (1954-2011) using the method of Lockwood (2008). Like that by Scafetta (2009), this fit allows for the climate response times (in this case by passing each input variation through a filter with a response time constant which is iterated in the fit); however, it differs in that it uses different input variations. In fact, the best-fit response time for each input was found to be near 1 year and constraining all inputs to the same response time generated an almost identical fit with fewer free parameters. The galactic cosmic ray flux is used to quantify the solar input as the data sequence is longer and more stably calibrated than the available TSI record, and there is a good (anti)correlation between the two (see Fig. 3). In addition, the El-Niño Southern oscillation (ENSO) can be regarded as an energy input into the surface layer that is quantified by the N3.4 index (based on the sea surface temperature in the equatorial Pacific). Figure 1 shows excellent agreement between observed and fitted variations for 1953-2011, and Fig. 2 shows that the dominant component of the fitted variation is anthropogenic and the solar contribution is small (and actually downward on average for this interval). The fit residuals shown in the bottom panel of Fig. 1 are attributed to internal variability. For this fit, we find that the contributions to the GMAST rise are in almost the same ratios as the radiative forcing changes over the interval. This means that the feedback factors required are approximately the same for all forcings (so $a_{\mathrm{S}} \approx a_{\mathrm{G}} \approx 2$ ). This multiple regression fit is subject to the same set of caveats as all others (i.e. selection effects of the choice of inputs, inter-correlations between inputs, nonlinear responses and overfitting of internal variability). However, it does demonstrate that a simple combination of known inputs can explain the observed GMAST variation (incidentally including any recent apparent

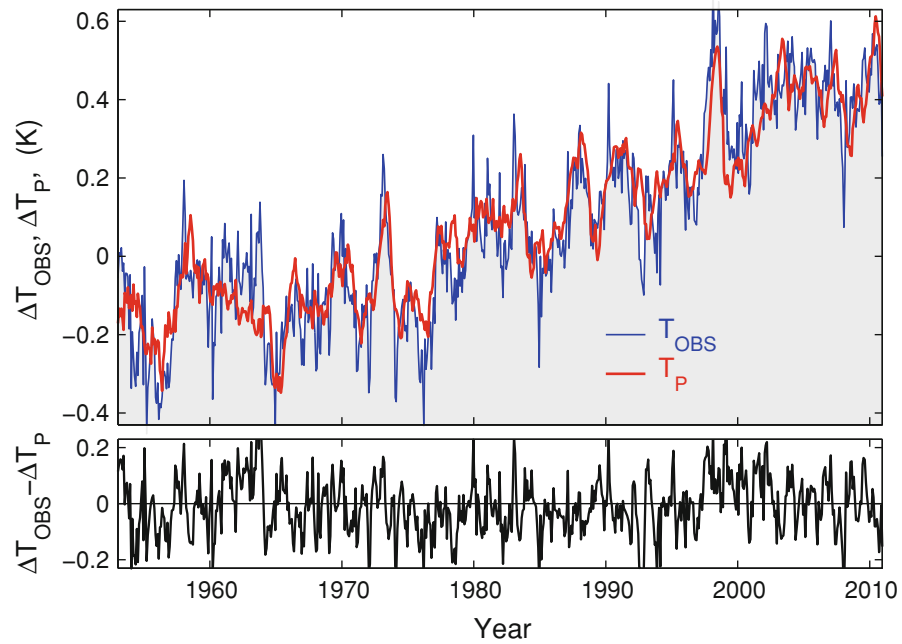

Fig. 1 Top observed $\left(T_{\mathrm{OBS}}\right.$, blue $)$ and fitted $\left(T_{\mathrm{P}}\right.$, red $)$ global mean air surface temperature $(G M A S T)$ variations for 1953-2011. The monthly observations are the HADCrut3v database (Brohan et al. 2006), and the fit is carried out using the procedure of Lockwood (2008) that allows for climate response times. Bottom the variation of the fit residuals $\left(T_{\mathrm{OBS}}-T_{\mathrm{P}}\right)$ 

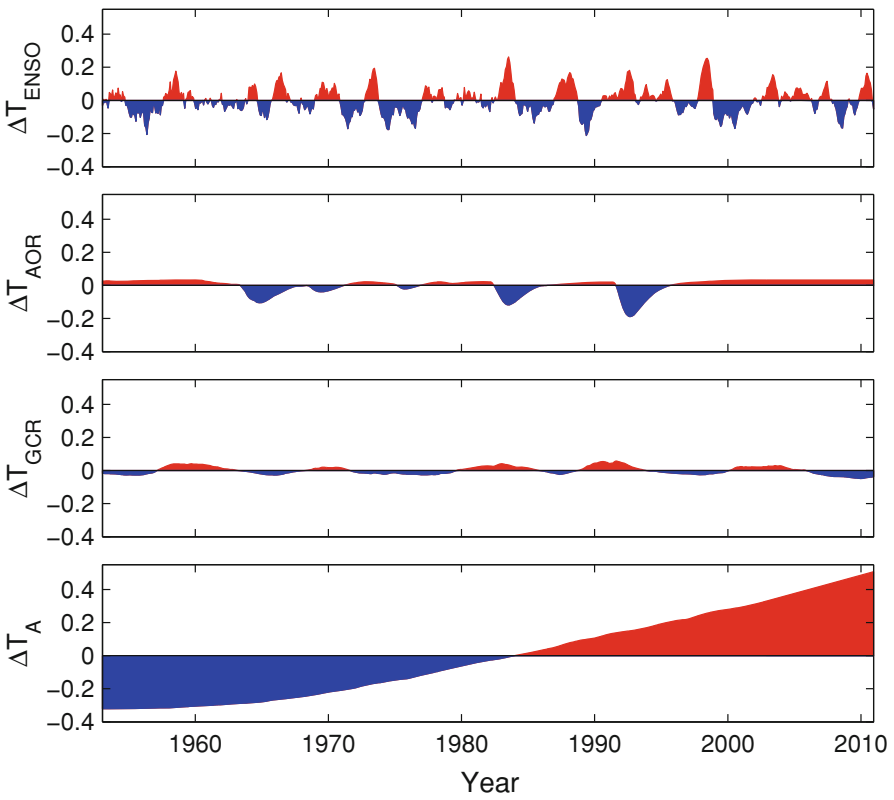

Fig. 2 The contributions to the fitted variation $T_{\mathrm{P}}$ in Fig. 1. Each panel uses the same $y$-axis scale to allow comparison (above/below average values are shown in red/blue), and each input parameter has been smoothed/lagged using its best-fit response time parameter. Fits are achieved with the Nelder-Mead search method. From top to bottom ENSO (input quantified by the N3.4 ENSO index), volcanoes (quantified by the global mean atmospheric optical depth, AOD); solar (quantified by GCR fluxes observed by neutron monitors), and anthropogenic (quantified by the GISS model E forcings for well-mixed trace greenhouse gases, land-use changes and man-made tropospheric aerosols). For comparison, the RMS fit residual $<\left(T_{\mathrm{OBS}}-T_{\mathrm{P}}\right)^{2}>^{1 / 2}$ is $0.10^{\circ} \mathrm{C}$ (see Fig. $1 \mathrm{~b}$ )

plateau) very well indeed and in a way that is consistent with the known radiative forcing changes. Notice that this analysis has not made use of any numerical climate model results.

To be fully rigorous, one has to move to "detection-attribution" studies, in which the effect of varying an input to a general circulation ocean-atmosphere climate model (GCM) must be detected above the internal variability of the climate system, as modelled by the GCM. Results do depend on which GCM is used, although there is also now considerable degree of agreement between the different models and, indeed, with the results shown in Fig. 2. A comprehensive review of detection-attribution methods and results is given as part of the IPCC 4th Fourth Assessment Report (Hegerl et al. 2007). Some key conclusions in this context are that (a) the combined effects of solar and volcanic forcings has resulted in a net cooling over recent decades; (b) models simulate much less warming over the 20th century in response to solar forcing alone than for greenhouse gas forcing alone (Cubasch et al. 1997; Broccoli et al. 2003; Meehl et al. 2003, 2004; Tett et al. 1999, 2002); (c) in combination, the greenhouse effect on surface temperatures is dominant over the solar effect (Stone et al. 2007a, b), although there is some debate about the precise contributions (Stott et al. 2003); and (d) the changes in the altitude profiles also reveal a dominant greenhouse gas effect (Jones et al. 2003).

Coupled ocean-atmosphere climate models (GCMs) have developed rapidly over the last 2 decades, and this has altered the details of the attribution of solar effects. In general, the derived solar-induced changes in GMAST have been small, even for the larger drifts in solar 
(a)

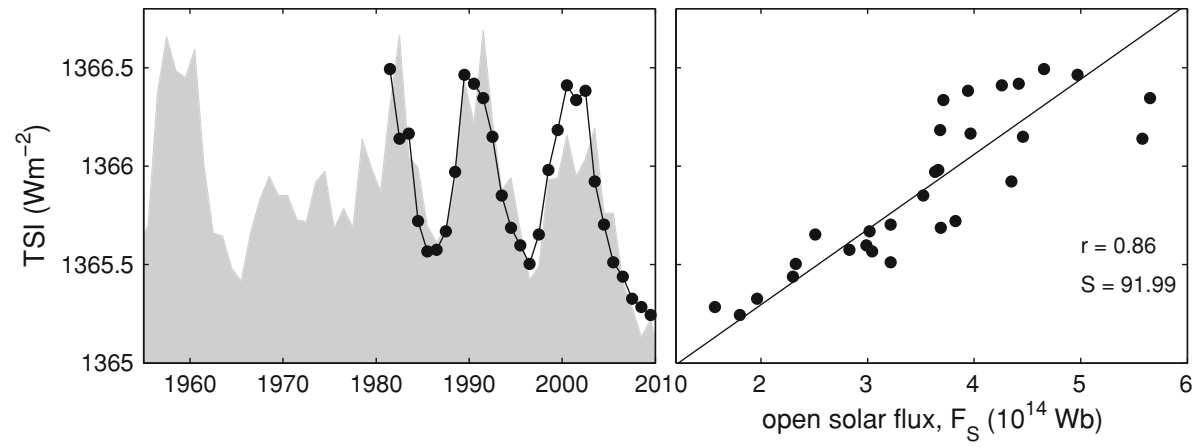

(c)

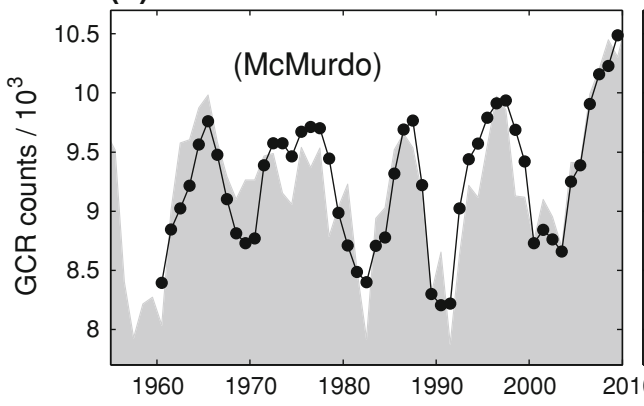

(b)

(d)

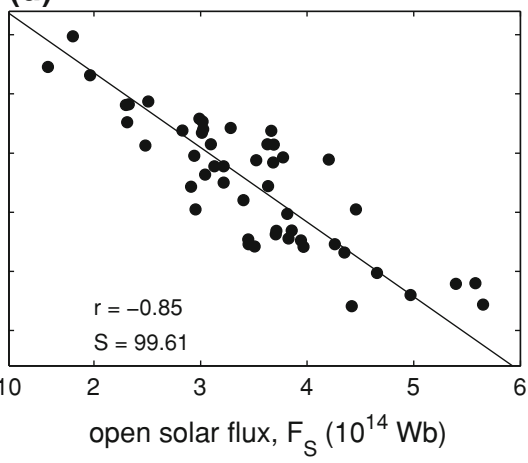

Fig. 3 The relationships between annual means of the open solar magnetic flux, $F_{\mathrm{S}}$, and (top) the total solar irradiance, TSI (here quantified using the PMOD composite: Fröhlich 2009) and (bottom) the galactic cosmic ray (GCR) flux (here quantified using the counts detected by the McMurdo neutron monitor in Antarctica). The left-hand panels show the time series, and in both cases, the best-fit linear regression of $F_{\mathrm{S}}$ is shown by the area shaded grey. The right-hand plots show the scatter plots with the best-fit linear regression line. The correlation coefficients $r$ and their significances $S$ (compared against the AR (1) noise model) are given (from Lockwood et al. 2010a)

radiative forcing predicted by the early TSI reconstructions (Wigley and Raper 1990). Full comparisons are not possible because the TSI reconstructions have evolved at the same time as the complexity and resolution of the models has increased. As expected, weaker solar effects are found for the smaller $\Delta \mathrm{S}$ inherent in the more recent TSI reconstructions (compare, for example, Wigley and Raper 1990 with Zorita et al. 2004 and/or Stendel et al. 2006). Examples of recent GCM experiments giving a relatively large "bottom-up" solar effect have been presented by Rind et al. (2008). The input solar forcing change between the Maunder Minimum and the present day used was $0.68 \mathrm{~W} \mathrm{~m}^{-2}$ (more than twice the consensus $\Delta f_{\mathrm{S}}$ discussed earlier) with an input of $1.9 \mathrm{~W} \mathrm{~m}^{-2}$ from total anthropogenic forcing, including $\Delta f_{\mathrm{G}}$. This solar forcing is well outside the range of $0.06-0.30 \mathrm{~W} \mathrm{~m}^{-2}$ quoted by Hegerl et al. (2007), and the Rind et al. experiments generally gave a relatively large solar contribution (near 30\%) to the total GMAST rise (the total GMAST rise also being larger than is observed). The tropical response, in particular, was much greater than observed, consistent with an excessive TSI change input to the experiments.

Rind et al. (2008) used a model with a coupled stratosphere at four different resolutions, to investigate various aspects of "top-down" solar cycle influence on the troposphere/ 
stratosphere system. The results show that the stratospheric response is highly repeatable and significant. Stratospheric westerly wind increases, driven by a greater equator to pole temperature gradient, were found to extend down into the troposphere and in some experiments the jet stream weakened and moved polewards. The predominant tropospheric response consisted of a warming of the troposphere, with coherent changes in regional precipitation. The tropospheric response was often not great, but was similar in all the different simulations. All runs revealed both top-down and bottom-up solar effects, but they account for only a small percentage of the total GMAST variance. A model described by Meehl et al. (2003, 2008, 2009) includes ocean-atmosphere coupling and with the stratosphere and suggests potential resonant connections between UV solar forcing and the ENSO oscillation, as also discussed by Emile-Geay et al. (2007) and White and Liu (2008a, b).

\section{Paleoclimate Studies and Solar Proxies}

For paleoclimate studies, it is important to bear in mind all the potential pitfalls listed in Sect. 2 of this review. However, there is an additional problem to consider with the data sequences, which is not a factor for direct observations, namely dating (van Geel and Mook 1989). Because record dates are uncertain, "wiggle matching" is often used (Kilian et al. 1995; Blaauw et al. 2003). Even if this is done with great care, such that the date of any one data point is not changed by more than the accurately computed dating uncertainty, there is inevitably a selection effect at work. This is because the adjustments are always made to improve correlations and not to degrade them. For this reason, there is a marked tendency for some correlations to degrade as the accuracy of the dating is improved.

An additional factor to bear in mind is that solar variability in paleoclimate studies is quantified using the abundance of cosmogenic isotopes, usually ${ }^{14} \mathrm{C}$ and ${ }^{10} \mathrm{Be}$, found in terrestrial reservoirs. ${ }^{10} \mathrm{Be}$ is a spallation product of galactic cosmic rays hitting atmospheric $\mathrm{O}, \mathrm{N}$ and $\mathrm{Ar}$ atoms; ${ }^{14} \mathrm{C}$ is produced by thermal neutrons, generated by cosmic rays, interacting with $\mathrm{N}$. About two-thirds of the ${ }^{10} \mathrm{Be}$ are formed in the stratosphere and about one-third in the troposphere from where precipitation times into the reservoirs are typically 1 year and 1 week, respectively. The deposition into any one reservoir is influenced, to some extent, by climate conditions (e.g., Vonmoos et al. 2006; Field et al. 2006; Aldahan et al. 2008; Heikkila et al. 2008). On the other hand, the ${ }^{14} \mathrm{C}$ generated by GCRs takes part in the carbon cycle and is exchanged with the two major reservoirs, the oceans and the biomass. Hence, the transport and deposition into the reservoirs where they are detected (for example, ancient tree trunks for ${ }^{14} \mathrm{C}$ and ice sheets in the case of ${ }^{10} \mathrm{Be}$ ) are vastly different for these two major cosmogenic isotopes. We can discount the possibility that matching variations in the isotope abundances in their respective reservoirs are similarly influenced by climate during their terrestrial life history, because the transport and deposition of each are so different. After allowance has been made to both series for the effect of geomagnetic field changes, the correlation between decadal means over the past millennium of the abundance of ${ }^{10} \mathrm{Be}$ and the production rate of ${ }^{14} \mathrm{C}$ is 0.81 (with the ${ }^{10} \mathrm{Be}$ leading, as expected, by about 10 years and a significance level exceeding 99\%) (Bard et al. 1997). This correlation also applies to the more recent data. For example, the solar modulation potentials (see review by Usoskin 2008) for $1600-1960$ derived from ${ }^{10} \mathrm{Be}$ and ${ }^{14} \mathrm{C}$ (as presented by Lockwood et al. 2011b) yield a correlation coefficient of 0.83 . The

${ }^{14} \mathrm{C}$ data are the means from tree cores in many parts of the world, but the ${ }^{10} \mathrm{Be}$ data are from two just ice cores, one from Antarctica and another from Greenland. However, the 
influence of regional deposition variations on the ${ }^{10} \mathrm{Be}$ abundance is known to be small because the correlation with ${ }^{14} \mathrm{C}$ is high. Thus, it is concluded that the correlations that are found for both isotopes are associated with the one common denominator in their production, namely the incident cosmic ray flux.

The abundances of these isotopes are routinely used in paleoclimate studies as a proxy indicator of solar irradiance (Bard et al. 2000). Lockwood (2006) showed that the relationship between production of the ${ }^{10} \mathrm{Be}$ cosmogenic isotope and TSI is monotonic but may not be linear, depending on the effect of unknowns in the long-term quiet Sun irradiance behaviour. The flux of the GCRs that generate the cosmogenic isotopes is modulated by three following influences (Beer 2006): (1) the interstellar flux of GCRs incident on the heliosphere; (2) the shielding by the heliosphere; and (3) the shielding by the geomagnetic field. The spatial distribution of the interstellar GCR fluxes in our galaxy is on a sufficiently large scale compared to distances moved by our solar system through the galaxy, which means that we can neglect variations on timescales of Myr and smaller. The geomagnetic field shield has varied on timescales of $10 \mathrm{kyr}$. This variation has, in the main, been gradual during the Holocene, although there have been shorter-lived weakenings of the field (which may be geomagnetic reversal onsets that did not develop) such as the Laschamp event around $40 \mathrm{kyr}$ ago. To allow studies of the remaining effect, solar variability, studies have corrected the cosmogenic isotope record to allow for the secular geomagnetic variations (e.g., Steinhilber et al. 2008, 2009).

Figure 3 investigates the relationship of GCRs and total solar radiance in modern data. The magnetic flux that leaves the top of solar atmosphere (the "open solar flux", $F_{\mathrm{S}}$ ) is the source of magnetic field in the heliosphere, and it is irregularities in this heliospheric field which scatter GCRs and shield them away from Earth. As a result, there is a good inverse relationship between $F_{\mathrm{S}}$ and the flux of GCRs (Rouillard and Lockwood 2004), which is demonstrated by the lower panel in Fig. 3. The upper part of Fig. 3 looks at the relationship between $F_{\mathrm{S}}$ and the total solar irradiance, TSI. This relationship is more indirect than that with GCR flux in that $F_{\mathrm{S}}$ is a small, and potentially variable, fraction of the field that threads the photosphere and thereby modulates the visible/IR emission of Sun (via the darkening effects of sunspots and the brightening effect of smaller magnetic flux tubes called faculae: Solanki et al. 2005; Wenzler et al. 2006). $F_{\text {S }}$ correlates well with TSI over the solar cycle (Lockwood and Stamper 1999; Lockwood 2002), and recent studies indicate that observed TSI does also reflect some of the longer-term drift in $F_{\mathrm{S}}$ (Fröhlich 2009). Modelling of the long-term variations (since the Maunder Minimum) in $F_{\mathrm{S}}$ and TSI (Vieira et al. 2011; Wang et al. 2005) provides support for the broad correlation between the two.

However, it should be noted that GCR fluxes and cosmogenic isotopes are not just indicators of TSI. Much of the magnetic field that modulates TSI as it passes through the photosphere also modulates solar UV emissions as it passes though the chromosphere. The UV part of the solar spectrum is much more variable than TSI and modulates ozone abundance, temperatures and winds in Earth's stratosphere (see review by Gray et al. 2010). Composites of observed UV spectral solar irradiance (SSI) had shown little variation in the spectral shape, such that at all wavelengths they exhibit similar temporal variations to TSI (Lean et al. 1997), and this has been reflected in centennial reconstructions of SSI (Lean 2000; Krivova et al. 2009). However, recent observations of the descent into the current "unusual" (for the space age) solar minimum (Lockwood 2010) cast doubt on this as they show more variability in the UV and considerable change in spectral shape (Harder et al. 2009). This implies that at the wavelengths responsible for stratospheric modulation, centennial variation may be greater than previously thought. These new data are from the SORCE satellite and are supported by observed changes in ozone abundance 
(Haigh et al. 2010). If confirmed, this is a considerable change in our understanding in spectral irradiance variability as it means that TSI change is predominantly caused by UV changes and that the changes at IR/Visible wavelengths are actually in the opposite direction to those in the UV and TSI. This contrasts sharply with previous models in which the waveform of temporal variations was taken to be similar at all wavelengths (Lean 2000; DeLand and Cebula 2008; Krivova et al. 2009). At present, there is no consensus as to how these new results should be used and incorporated into models. Schmidt et al. (2011) argue that as the SORCE data come from one instrument (the Spectral Irradiance Monitor, SIM) and are for a limited period (the declining phase of cycle 23) it is premature to act upon them. However, it should be noted that the prior data were also limited in temporal and wavelength coverage, and there are doubts about their accuracy at some wavelengths (DeLand and Cebula 2008). Unfortunately, the wavelength band in which inter-calibrations can be carried out is very limited (Lockwood 2011a), and a homogenised data sequence of spectral irradiance will have to rely heavily on modelling (Krivova et al. 2011), at least until new space-based instrumentation can be commissioned. At the time of writing, the latest data from SIM (http://lasp.colorado.edu/sorce/data/) during the rising phase of solar cycle 24 show a reverse of the changes seen in the declining phase of cycle 23 , despite the low activity levels of the new cycle (Owens et al. 2011). This implies that long-term calibration drift is not the cause of the radically different trends in the SIM data. SRPM (Solar Radiation Physical Modelling) analysis combines information of the features in the solar chromosphere with physics-based solar atmospheric spectral models to compute the emergent intensity spectrum, and initial work suggests that it is able to reproduce trends observed by SIM and that solar active regions are not the only cause of the observed variations (i.e. changes in the quiet-Sun internetwork/network radiance are involved).

The trends suggest that the open solar flux $F_{\mathrm{S}}$ may also be related to long-term variations in solar UV emissions (Lockwood et al. 2010b), and hence cosmogenic isotopes may be a proxy indicator of UV effects. In addition, cosmogenic isotopes would, of course, be a direct indicator of any cloud modulation by GCRs, where such a mechanism to be active, and $F_{\mathrm{S}}$ is highly anti-correlated with GCR fluxes (Rouillard and Lockwood 2004). Recent results relating to the GCR-cloud mechanism are discussed in Sect. 8.

This review focuses on recent work that uses the open solar flux $F_{\mathrm{S}}$ to quantify solar activity. From the discussion above, $F_{\mathrm{S}}$ can reveal effects associated with changes in TSI, UV spectral irradiance, GCRs or even SEP fluxes. In addition, $F_{\mathrm{S}}$ is highly correlated with mean geomagnetic activity levels (indeed it is reconstructed before the start of space observations using geomagnetic data, Lockwood et al. 2009; Lockwood and Owens 2011) and so is likely to be linked to reports of climate effects associated with geomagnetic activity (e.g., Seppälä et al. 2009; Bochníček and Hejda 2005; Thejll et al. 2003).

A great many studies have indicated that solar variations had an effect on pre-industrial climate throughout the Holocene (the warm interval since the last ice age). These studies have been carried out in many parts of the world and employ a huge variety of paleoclimate proxies. They will not be discussed here, and the reader is referred to the recent review by Lockwood (2012). The most interesting of these studies employed terrestrial data that are indicators of more than just local climate and/or where matching signals are seen at geographically separated sites. Some studies have used proxy data from very large numbers of sites to reconstruct temperature maps, cross-calibrating with early observational data (e.g., Mann et al. 2009). Nevertheless, a key point to note is that most paleoclimate evidence is local, or at best regional, and not global in scope.

Section 4 discussed how solar influence on climate on a global scale has been relatively minor and how studies that arrive at a different conclusion have been flawed and not 
robust. Section 6 reviews the growing evidence in modern data for solar influences on some regional and seasonal climates.

\section{Regional Climate Effects}

Using both a climate model and empirical reconstructions, Shindell et al. (2001a, b) found that even though solar-induced GMAST changes are small (below about $0.3^{\circ} \mathrm{C}$ ), regional temperature changes associated with solar variability can be quite large. In their model, these occur primarily through a forced shift towards the low index state of the North Atlantic oscillation (NAO) as solar irradiance decreases. This leads to lower temperatures over the northern hemisphere continents, especially in winter $\left(1-2^{\circ} \mathrm{C}\right)$, in agreement with historical records and proxy paleoclimate data for surface temperatures.

For post-industrial measurements, North and Stevens (1998) applied optimal signal detection theory to data from 36 regions around globe but found the solar signal was small and not highly significant. On the other hand, multivariate fits by Lean and Rind (2008) and Lean (2010) do find strong solar responses in certain regions. Figure 4 shows the multiple regression maps to modern AST (Air Surface Temperature) data by Lean (2010). These are derived in a similar way, and using the same inputs, as the fits to global means of AST (i.e. the GMAST) shown in Figs. 1 and 2. The maps in Fig. 4 are for annual mean data. The top panel shows that the response to a strong El-Niño event is, obviously, dominated by the equatorial Pacific, but there is also strong North Pacific cooling and continental North American warming. The second panel shows that a large equatorial volcanic eruption produces widespread cooling from $40^{\circ} \mathrm{S}$ to $70^{\circ} \mathrm{N}$, especially in North America and the North Atlantic Ocean, but strengthened westerly winds, and a more positive phase of the NAO produces warming in the northern Eurasian continent. The bottom panel shows that the response to anthropogenic effects is widespread and particularly strong in the northern hemisphere at middle to high latitudes, as predicted by GCMs (e.g., Stott et al. 2000). The third panel shows that the response to solar variability is strongest at middle latitudes (near $40^{\circ}$ ) in both the northern and southern hemispheres, in the vicinity of the interface of the Hadley and Polar cells (Gleisner and Thejll 2003; Haigh 2003). We would expect climate to respond to solar variability with distinct seasonality because the lower latitudinal gradient of solar energy in summer means that dynamical processes are then not as strong. Remember that, as for all such multiple regression fits, the procedure may have overfitted decadal-scale internal oscillations with the input solar variation and so may have overestimated the response. The most noticeable feature is that the northern hemisphere response is much greater than the southern, with a strong longitudinal variation such that the biggest effect is over Europe and western Asia (referred to hereafter as Eurasia). Statistically significant signatures of multidecadal solar activity changes in atmospheric temperatures in Eurasia have recently been reported by Kossobokov et al. (2010) and Le Mouël et al. (2008, 2009, 2010) but Yiou et al. (2010) and Legras et al. (2010) argue that they do not survive proper null-hypothesis testing.

Climate fluctuations for different regions tend to cancel, giving global means that are much less variable than regional ones and which more clearly reveal trends. Figure 5 stresses how different the behaviour of a regional/seasonal climate in Europe can be from the global or hemispheric means. The plot uses winter (December-January-February, DJF) means, $T_{\mathrm{DJF}}$, of the Central England Temperatures (CET) which is the world's longest instrumental record and extends back to 1659, at the start of the Maunder Minimum (Manley 1974; Parker et al. 1992). The CET measurements cover a spatial scale of order 

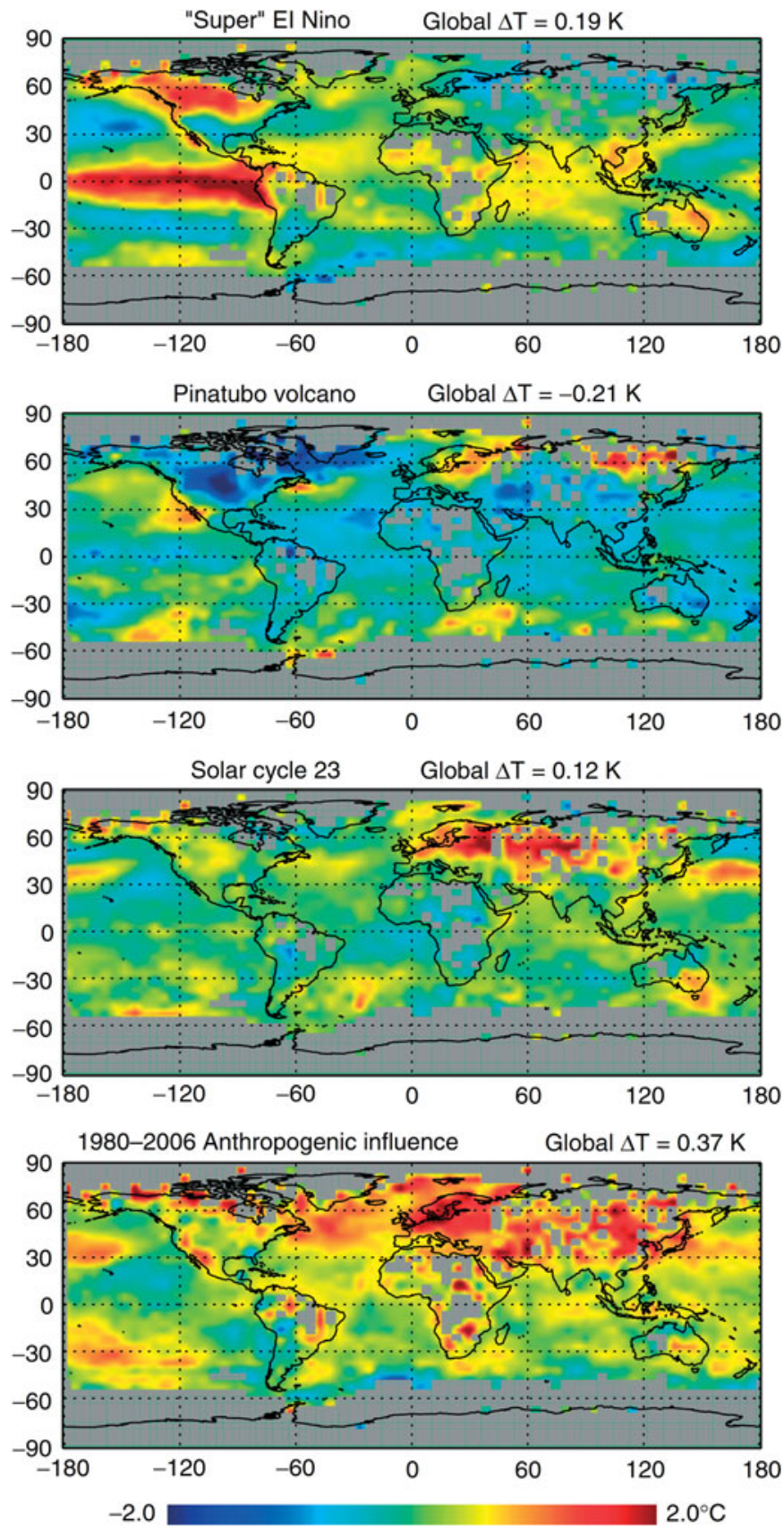

Fig. 4 Maps of the global responses to given features in the input data series in Fig. 2 from multiple regression analysis, which give a GMAST contribution of $\Delta T$ which is given at the top of each panel: (from top to bottom) a the "super-El-Niño" event of 1998, b the Pinatubo volcanic eruption, c solar cycle 23 and d the net anthropogenic forcing over the period 1980-2006. These are very similar in form to the maps of the regression coefficients of GMAST presented by Lean and Rind (2008) for the annual time series data shown in Fig. 2 (after Lean 2010) 
(a)

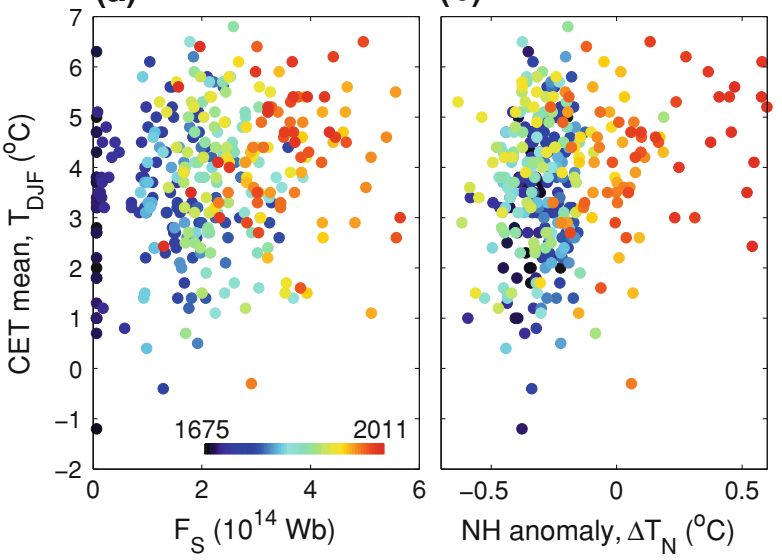

(c)

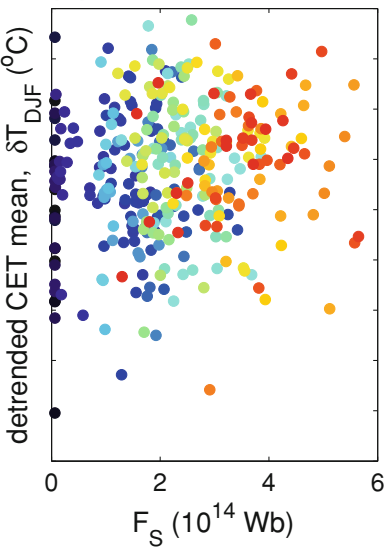

Fig. 5 Scatter plots of mean winter Central England temperature (CET), $T_{\mathrm{DJF}}$, as a function of a open solar flux, $F_{\mathrm{S}}$ and $\mathbf{b}$ the hemispheric mean surface temperature anomaly $\Delta T_{\mathrm{N}}$ (the HADCRUT3v reconstruction is here extended to before 1850 using the median of a basket of proxy paleoclimate reconstructions). Points are coloured according to the date using the scale shown in $\mathbf{a}$. The line in $\mathbf{b}$ is the ordinary least squares linear regression fit, and the grey area bounds the uncertainty range set by the range of the proxy reconstructions for $\Delta T_{\mathrm{N}}$ prior to 1850 . The correlation coefficients for $\mathbf{a}$ and $\mathbf{b}$ are low at 0.23 and 0.25 (significant at the 99.1 and $99.6 \%$ levels using the AR (1) noise model). In the case of $\mathbf{b}$, this demonstrates the great variability of a regional/seasonal temperature around a global-scale mean. $\mathbf{c}$ is the same as a, for the detrended winter CET data $\delta T_{\mathrm{DJF}}$, where the detrending allows for the hemispheric change $\Delta T_{\mathrm{N}}$ and uses the regression line shown in b. c shows that, even after allowing for the hemispheric trend, most of the coldest winters in central England occur at lower solar activity, as quantified by $F_{\mathrm{S}}$. Lockwood et al. (2010a) test this against the null hypothesis that $F_{\mathrm{S}}$ has no effect on winter CET values and show that this tendency is statistically significant at around the $95 \%$ level. Several tests were carried out on the differences between distributions of $F_{\mathrm{S}}$ above and below various thresholds in $\delta T_{\mathrm{DJF}}$. These were then repeated for the differences between distributions of $\delta T_{\mathrm{DJF}}$ above and below various thresholds in $F_{\mathrm{S}}$

$300 \mathrm{~km}$ which makes it a "small regional" climate indicator. In winter, the NAO, and associated changes in thermal advection, contribute to a large fraction of the observed variability of CET (Karoly and Stott 2006). Comparison of parts (a) with (b) of Fig. 5 shows that $T_{\mathrm{DJF}}$ correlates with both open solar flux $F_{\mathrm{S}}$ and the hemispheric mean surface temperature $\Delta T_{\mathrm{N}}$. However, the correlation is very weak in both cases. Lockwood et al. (2010a) show that there is a subtle solar influence on winter CET in that it is statistically significant that more cold winters, relative to the hemispheric trend, occur when the open solar flux is low (i.e. when solar irradiances are thought to be low and GCR fluxes are high). This can be seen by the lack of points in the bottom-right corner of Fig. $5 \mathrm{c}$ which was found to be significant at more than the $95 \%$ level using 6 different tests against the null hypothesis. Figure 6 shows that both surface temperature and surface pressure in winter (DJF means) in ERA-40+ re-analysis data for 1957-2001 show a clear influence of $F_{\mathrm{S}}$ (Woollings et al. 2010b). Figure 6a shows that difference in the means for low solar activity (lower tercile of the $F_{\mathrm{S}}$ distribution) minus that for high solar activity (the upper tercile of that distribution). Temperatures are lower in Eurasia by up to $4^{\circ} \mathrm{K}$, but note that they are higher in Greenland by up to $3^{\circ} \mathrm{K}$. Figure $6 \mathrm{~b}$ shows the corresponding plot, sorted using the NAO index. In fact, the temperature drops in central Europe are not as large for the NAO sort, being up to about $2^{\circ} \mathrm{K}$. The significances of the differences exceed $95 \%$ over a more extensive area in Eurasia for the solar than the NAO pattern. It is also interesting to 


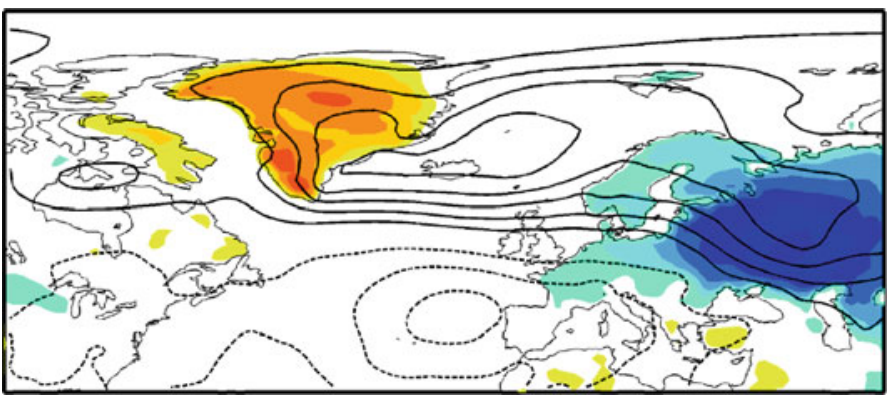

(b)

NAO: NAOI High - NAOI Low

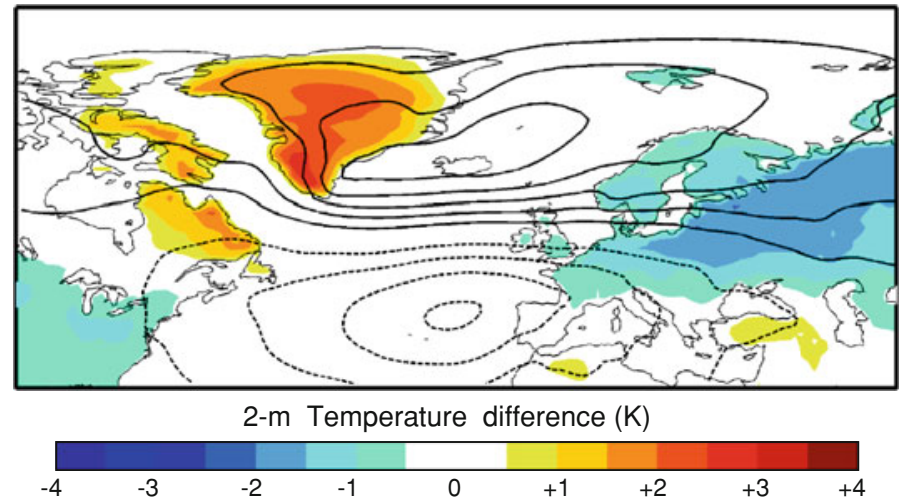

Fig. 6 a Composite difference maps of winter (DJF) means of mean surface level pressure (MSLP, contours $1 \mathrm{hPa}$ apart) and 2-m temperature (colour map) between low- and high-solar conditions defined by the lower and upper terciles of the open solar flux, $F_{\mathrm{S}}$. b Scaled anomalies associated with the NAO for comparison, in this case the two subsets are for the lower and upper terciles of the NAO index. Data are from the European Centre for Medium-range Weather Forecasting ERA-40 reanalysis data set (Uppala et al. 2005) extended to cover 44 complete winters (1957/1958 to 2000/2001) using operational data (from Woollings et al. 2010b). A bootstrap test was employed, resampling the sets of winters in order to estimate the sampling uncertainty, to test whether the solar pattern in a was different from that associated with the $\mathrm{NAO}$ in b: this found that the two patterns are significantly different at the $93 \%$ level

note that the perturbation circulation pattern for the solar effect is similar to, but still significantly $(>93 \%)$ different from, that for the NAO, reaching further to the East.

Early instrumental records from the Maunder Minimum indicate an increased frequency of easterly winds influencing the UK winter temperatures during exceptionally cold winters (Slonosky et al. 2001). This is consistent with the circulation perturbation in Fig. 6 and has also been deduced from indirect proxies (Luterbacher et al. 2001), including the spatial patterns of changes in recorded harvest dates (Wanner et al. 1995). This strongly suggests a link with the incidence of long-lived winter "blocking" events in the eastern Atlantic at low solar activity. Blocking episodes comprise extensive and quasi-stationary anticyclones which can persist for several weeks, leading to extended cold periods in winter as the mild maritime westerly winds are replaced by continental north-easterlies and the land surface cools under cloudless skies. These changes are associated with a meander in the jet stream in the upper troposphere and lower stratosphere, such that its usual eastward (westerly) 
flow becomes south-westward around the longitude of the event centre (Woollings et al. 2010a). Long-lived Atlantic blocking events at more eastward locations have been found to be more prevalent at sunspot minimum than at higher solar activity, and this leads to colder winters in Europe (Barriopedro et al. 2008). Note, however, that to the west of the event centre warm air is drawn up from the south-west and hence if the blocking event centre moves exceptionally far to the east temperatures in western Europe may rise rather than fall: the region where CET is measured is quite close to the average longitude of blocking event centres and, although it shows a net cooling effect for lower solar activity, this is much smaller than the effect found further to the east. This evidence suggests that solarinduced perturbations modulate the North Atlantic jet stream and hence the occurrence of blocking. Other evidence supports this idea. For example, the effects of the changed position and frequency of blocking events may be seen as a manifestation of modes of lowfrequency circulation variability which have been found to respond to solar activity giving increased/decreased frequencies of easterly/westerly circulation patterns over Europe under low-solar activity conditions (Huth et al. 2006, 2008). Figure 7 (from Woollings et al. 2010b) studies changes in the occurrence of DJF blocking events, using the means of the blocking index of Berrisford et al. (2007) from the same data set as used in Fig. 6. The anomaly, compared to the overall mean, for the high (upper tercile) $F_{\mathrm{S}}$ subset is shown on the left and for low (lower tercile) $F_{\mathrm{S}}$ subset the right. For the high $F_{\mathrm{S}}$ winters, the blocking occurrence is up to $6 \%$ lower than the average, in a restricted region in the eastern North Atlantic and over North-Western Europe. On the other hand, for the low $F_{\mathrm{S}}$ winters, the same region shows the blocking occurrence is up to $8 \%$ higher. Monte-Carlo tests show these changes are significant at the $99 \%$ level. This modulation of the occurrence of winter blocking events is highly significant and provides a good explanation of the modulation of the surface temperatures and pressures seen in Fig. 6.

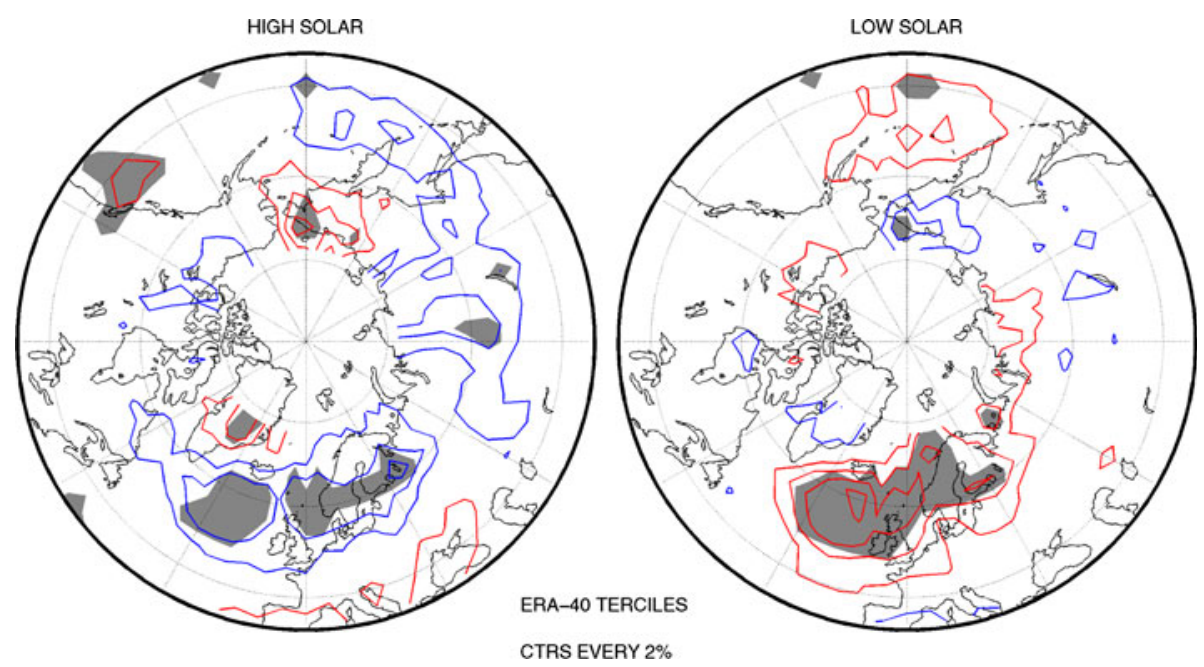

Fig. 7 Composite northern hemisphere anomalies, relative to the overall mean, of blocking episode frequency (defined using the blocking index of Berrisford et al. (2007) from the same data set as used in Fig. 6). Contours in the left and right hand panels show, respectively, the anomalies for the high- and lowsolar activity winters, defined as the upper and lower terciles of the open solar flux, $F_{\mathrm{S}}$, distribution. Contours are drawn every $2 \%$, with positive/negative contours in red/blue, respectively, with the zero contour omitted. The grey area shows where the anomalies are significant at the $99 \%$ level, defined using a Monte-Carlo technique (from Woollings et al. 2010b) 
Winter CET values are known to be strongly modulated by the NAO (Karoly and Stott 2006), and modelling has shown that stratospheric trends over recent decades, along with downward links to surface, are indeed strong enough to explain much of the prominent trend in the NAO and hence regional winter climate in Europe between the 1960s and the 1990s (Scaife et al. 2005). Furthermore, tropospheric blocking episodes are known to influence the stratosphere, and there have been strong suggestions that the coupling works both ways, such that they are also influenced by the stratosphere (Woollings et al. 2010a). In addition, various empirical studies have reported solar modulation of the NAO (Ruzmaikin and Feynman 2002; Thejll et al. 2003). The top-down mechanisms implied are discussed further in Sect. 7 and are likely to be connected to the centennial scale variations and phenomena seen in Europe during the Maunder Minimum. For example, the GCM runs experiments by Rind et al. (2008) produce a relative negative phase of the NAO during the Maunder Minimum which contributes to predicted lower European winter temperatures at that time.

Mann et al. (2009) studied regional climate on a global basis using paleoclimate data from tree trunks, ice sheets, corals and sediments from over 1,000 sites. They searched for solar influence on pre-industrial climate by comparing the difference between the "little ice age" pattern (which they define as 1400-1700 AD) and that for the "mediaeval maximum" (which they take to be 950-1250 AD): They find it shows a pattern that has some similarities to Fig. 4c. The reconstruction by Steinhilber et al. (2009) of TSI during the Holocene from cosmogenic isotopes gives a difference of $0.5 \mathrm{~W} \mathrm{~m}^{-2}$ between the means for these two intervals. However, the temporal variations deduced by Mann et al. do not agree particularly well with the Steinhilber et al. TSI reconstruction. For example, they do not show any feature at the time of the solar Maunder Minimum (circa 1645-1715 AD). Mann et al. argue that the spatial pattern is consistent with a relative positive/negative NAO-AO atmospheric circulation anomaly during the mediaeval maximum/little ice age, respectively, associated with annular bands of sea-level pressure anomalies that are positive/negative in the subtropics and mid-latitudes, and negative/positive at subpolar latitudes. This has been seen in model simulations as a dynamical response to imposed solar irradiance effects on ozone photochemistry (Shindell et al. 2001a, b).

Detection-attribution techniques have been applied on a regional and seasonal basis. Studies to date have generally found the solar contributions to be smaller than those of volcanoes and sulphate aerosols as well as smaller than the effects of greenhouse gas changes and land-use change. Hegerl et al. (2011) used a multifingerprint technique to detect a solar response in Europe, but in summer temperatures rather than the winter response discussed above. This was not robust to all tests and so remains speculative. It will be interesting to see whether these results change as models with better representation of the stratosphere are employed and when better characterisation of spectral solar irradiance becomes possible.

\section{7 “Top-down” Solar Forcing}

The dynamical coupling across the tropopause (Shepherd 2002) means that stratospheric forcing can influence the underlying troposphere (e.g., Hartley et al. 1998; Song and Robinson 2004; Matthes et al. 2006; Haigh and Blackburn 2006), and under some circumstances, robust tropospheric responses are indeed predicted by models. Observational studies show that stratospheric perturbations (e.g., stratospheric warmings) typically last at least a month, and on average, tropospheric effects are seen approximately 2 weeks later 
(e.g., Baldwin and Dunkerton 2001). Note, however, that the strong, two-way coupling across the tropopause means that the appearance of the change first in the stratosphere is not necessarily an indication that the stratospheric changes are driving those in the troposphere. The latitudes of tropospheric jet streams have been shown to be sensitive to the solar forcing of stratospheric temperatures (Haigh 1994, 2003; Poore et al. 2004). This could occur through disturbances to the stratospheric polar vortex (Gray et al. 2004), which can propagate downwards to affect the tropospheric jets (Plumb and Semeniuk 2003) or through the effects of stratospheric temperature changes on stratospheric winds and the refraction of tropospheric eddies (Kushner and Polvani 2004; Simpson et al. 2009). Models (e.g., Shindell et al. 2001a, b) predict that perturbations can descend from the stratosphere to the surface by altering the propagation of planetary waves coming up from the surface, an effect that has been observed in data (Perlwitz and Harnik 2003). However, models that do not yield realistic stratospheric dynamics fail to capture these wave flux changes. The tropospheric response is reduced when planetary waves are suppressed in the stratosphere by additional damping or when the strength of the stratospheric jet is increased. The models show that the stratosphere could play a crucial role in recent trends. For example, Scaife et al. (2005) have demonstrated that stratospheric trends over recent decades, along with downward links to surface, are indeed strong enough to explain much of the prominent trend in the NAO and hence regional winter climate in Europe between the 1960s and the 1990s.

A wide variety of tropospheric responses has been suggested. Recent numerical modelling by Ineson et al. (2011) has simulated the effect of the large decline in the stratosphere-effective UV band inferred from the recent SIM/SORCE measurements by Harder et al. (2009) and Haigh et al. (2010). As discussed in Sect. 5, there is debate as to whether these observations exaggerate the variability of the UV irradiance but, on the other hand, the modelling maintains constant ozone concentrations, and this will underestimate the effect. The modelled response to the decreasing solar UV begins in the upper stratosphere and lower mesosphere, consistent with ERA-40+ reanalysis data. This signal is largest in the tropics (Frame and Gray 2010; Lockwood et al. 2010b) and so gives a relative decrease in the pole-to-equator temperature gradient for lower solar activity. This response is reproduced in the model and require a weak easterly wind anomaly in the subtropical zonal mean circulation in the upper stratosphere. As predicted and inferred by Kodera (2002) and Kodera and Kuroda (2005), this anomaly amplifies as it propagates polewards and downwards during autumn and winter, giving a weaker polar vortex in December-January at solar minimum. Ineston et al. use the modelled Eliassen-Palm (EP) flux divergence to show that this downward propagation and amplification of the wind anomaly is associated with altered planetary wave activity.

The number and fluence of solar energetic particle events (SEPs) also vary with the level of solar activity quantified by $F_{\mathrm{S}}$ (Barnard et al. 2011). SEPs are directed towards Earth poles by the geomagnetic field where they generate nitrates on hitting Earth's atmosphere as demonstrated, for example, in observations by Mlynczak et al. (2003). These nitrates are seen to migrate downwards over time (Siskind et al. 2000; Funke et al. 2005), resulting in catalytic destruction of stratospheric ozone (Callis et al. 2000). Large SEP events generate considerable transient polar ozone depletions, which persist in winter until UV irradiance of the polar stratosphere resumes (Jackman et al. 2006, 2008; Randall et al. 2005, 2007). Recently, Seppälä et al. (2009) reported changes in polar surface temperatures which they associate with large SEP events. It should be noted that they used geomagnetic activity indices as indicators of the probability of SEP fluence, and these correlate highly with the open solar flux $F_{\mathrm{S}}$. Thus, it is likely they are observing the same 
phenomenon as reported by Lockwood et al. (2010a), Woollings et al. (2010b) and Bochníček and Hejda (2005) but are using an interpretation based on the model predictions of SEP effects by Rozanov et al. (2005, 2012). Similarly, the effect reported by Lu et al. (2008) which they attributed to the solar wind could well be via a correlation with open solar flux. In this context, it is interesting to note that the effects of SEPs may also be caused by other precipitating energetic particles, including GCRs or energetic electrons energised by the solar wind (see review by Rozanov et al. 2012, and references therein). Chemical and dynamical modelling of the effects of energetic particles has yielded a surface temperature perturbation pattern similar to that shown in Fig. 6 (Rozanov et al. 2012).

\section{Cosmic Ray Modulation of Clouds}

A long-standing suggestion is that cosmic rays can aid the formation of clouds (see reviews by Ney 1959; Carslaw et al. 2002; Kirkby 2007). This would be a highly significant effect because clouds modulate Earth's energy balance by changing the albedo $A$ and by enhancing the infrared greenhouse trapping effect. The balance between these two competing effects is dependent on the cloud altitude: For low clouds the albedo effect dominates (such that more cloud is a cooling effect), whereas for high-altitude clouds the greenhouse trapping effect dominates (so that more cloud gives warming). A great many papers have been written about low-altitude global cloud cover arguing that it shows a solar-cycle variation, consistent with GCR modulation of the growth of cloud condensation nuclei (CCN) (Svensmark and Friis-Christensen 1997; Svensmark 2007; Marsh and Svensmark 2000, 2003, 2004). These studies have been based on the available satellite data after 1983, which give global coverage, and so still cover something less than three solar cycles. Other studies find no significant effect (Sloan and Wolfendale 2008; Kernthaler et al. 1999; Kristjánsson and Kristiansen 2000; Sun and Bradley 2002, 2004; Kulmala et al. 2010). A third set of studies find significant correlations but only in restricted regions (Erlykin et al. 2010; Kristjánsson et al. 2008), whereas a fourth set report a solar-cycle variation but find it to be more consistent with solar UV irradiance variability (de Jager and Usoskin 2006; Erlykin et al. 2010; Udelhofen and Cess 2001). Voiculescu et al. (2006) argue that both UV and GCRs have an effect. Harrison (2008) detected a weak 1.68-year oscillation in the long (1947-1990) diffuse fraction data series from the Lerwick (maritime) station - an oscillation found in the open solar flux and GCR fluxes but not in the SSI or TSI variations (Rouillard and Lockwood 2004). Hence, this supports a direct effect of GCRs rather than irradiance changes. It is expected that any effect would be more significant in clean maritime air where there is a shortage of CCNs for water vapour to condense on, and air ions generated by GCRs may be more significant factor (Kazil et al. 2006; Laken et al. 2009).

The arguments against such direct cosmic ray-cloud connection have been: 1 . Given the atmospheric supersaturations, there is no established mechanism that can cause the effect. 2. The inter-calibrations involved in the composite cloud-cover data set used render it unsuitable for this type of long-term variability analysis (e.g., Klein and Hartmann 1993). 3. The data sequences are too short and so the significance of the correlations is low. (For example, Sun and Bradley $(2002,2004)$ show that the uniquely high cosmic ray-cloudcover correlation in the period 1983-1999 over the Atlantic Ocean is greatly weakened when an extended data set is used.) 4. Periods of low geomagnetic field, particularly the Laschamp event (Nöel and Tarling, 1975) which at $40 \mathrm{kyr}$ ago is the most recent and well 
studied, gave enhanced GCR fluxes in the Earth's atmosphere but did not influence climate in the Greenland area (Beer 2006). Of these objections, only 4 argues that such a mechanism is not effective: $1-3$ all argue that the evidence in its favour is inadequate. In relation to 4 , there is some evidence that the failure to see an effect of the Laschamp event (Wagner et al. 2001) may have been a local characteristic of the climate in the Greenland area (Christla et al. 2004). Other studies give indications of an influence of the geomagnetic field on pre-industrial climate. Recent reports of associations between the main geomagnetic field and climatic changes over the last three millennia (Haug et al. 2001; Gallet and Genevey 2007 Gallet et al. 2005, 2006; Courtillot et al. 2007) would be significant, if they survived robust null-hypothesis testing, because they would be via GCR effects and unrelated to solar irradiance changes. These changes have also been linked to latitudinal motions of the inter-tropical convergence zone (Haug et al. 2001). Harrison and Stephenson (2006) found evidence for a small GCR effect on diffuse fraction measurements at a variety of maritime UK meteorological stations (for 1951-2000) and Harrison et al. (2011) have found the base of some type of clouds is lowered by higher cosmic ray fluxes. As these are homogeneous sequences of simple measurements, this does counter objection (2) to some extent; however, the effect was small.

In addition to the solar-cycle variation in GCRs, there are sudden decreases in GCR fluxes over periods of a few days called Forbush decreases. These have been reported as giving responses in cloud data, both ground-based (Veretenenko and Pudovkin 1997) and from satellites (Svensmark et al. 2009), in "compositing" analyses (also called "superposed epoch" and "Chree" analysis). The problem with these studies (particularly if a satellite data set is employed) is that there are very few large Forbush decreases, and the results appear to be dominated by one or two events in the intervals of available satellite data. This means that statistical significance is very low. The long delay of the putative effect is also a major puzzle. Brown (2008) reports that $3 \%$ of cloud variability on short timescales could be associated with GCRs, whereas Calogovic et al. (2010) find no response at all. The potential importance of this effect is that there are long-term changes in the open solar flux $F_{\text {S }}$ (Lockwood et al. 2009; Lockwood and Owens 2011) that yields the long-term changes in GCRs (McCracken and Beer 2007; Muscheler et al. 2007; Steinhilber et al. 2008) which could introduce long-term changes in climate if the mechanism was to be sufficiently effective.

The best chance of answering objection (1) is the CLOUD experiment at CERN (Duplissy et al. 2010), which has just begun to study the "ion-aerosol clear-air" mechanism. The first results have just been published (Kirkby et al. 2011). The results have some fascinating new insights into effects in the boundary layer, but do not say much about the growth of water droplets in low-altitude cloud in the troposphere. Through the influence of sulphuric acid, ionisation was shown to enhance the rate of water droplet growth at the temperatures characteristic of middle troposphere. However, the ion-induced aerosols only grew to about $2 \mathrm{~nm}$, and to grow into droplets large enough to influence incoming or outgoing radiation to Earth, would be far too slow because there is not enough sulphuric acid in the atmosphere (Pierce and Adams 2009). As yet, the experiment is not reproducing the true mix of constituents in the mid-troposphere, so the results are highly provisional. Other proposed mechanisms involving the atmospheric electric field have been proposed (Harrison 2000) but have not yet been investigated.

The cloud-cosmic ray suggestion increasingly fails to match observations. The correlation between the solar-cycle variation and global cloud-cover estimates has degraded 
rapidly in the more recent data (Gray et al. 2010). For each piece of evidence in its favour, an equal or greater number of studies fail to find the effect. Only studies finding rather subtle effects on cloud edges survive proper null-hypothesis testing. Lastly, we note that GCR-cloud effects would have shown up in the multivariate fits of GMAST shown in Figs. 1 and 2, which found only a weak solar response (indeed in these fits, the solar input was even quantified using GCR fluxes). In addition, even if the GCR-cloud mechanism was responsible for the effect that was seen, the global regression map (Fig. 4c) generates a major issue. Larger GCR fluxes would have been expected near the poles, where geomagnetic shielding of GCRs is weaker and with no longitudinal effects (with the possible exception of in the south Atlantic geomagnetic anomaly). Hence, additional effects, such as spatial variations in aerosols, would have to be invoked to explain maps such as shown in Fig. 4c.

\section{The Future}

We have no predictive models of the solar dynamo (see review by Weiss and Thompson 2009) and so can only make empirical analogue forecasts of future solar output changes. From solar-induced variations of cosmogenic isotopes over the past $10^{4}$ years, Lockwood (2010) and Barnard et al. (2011) have deduced that there is an $8 \%$ chance that the Sun will return to Maunder Minimum conditions within 50 years. The recent evolution of solar cycle 24 indicates that the Sun may well be following such a trajectory (Owens et al. 2011). Feulner and Rahmstorf (2010) and Jones et al. (2012) have used GCMs and EBMs to predict that this will offset anthropogenically rising global temperatures by no more than about $0.2^{\circ} \mathrm{C}$ in the year 2100 , relative to what would happen if the solar output remained constant. Similarly, Lean and Rind (2009) find that the solar decline would delay the arrival at a given temperature level by no more than about 5 years. Thus, these predictions show that continued solar decline will do little to alleviate anthropogenically driven global warming. However, the decline should do much to end the debate about the fraction of global warming that can be attributed to solar change. For the first time since about 1900, long-term solar and anthropogenic trends are now in opposite directions. Non-robust fits will fail sooner rather than later because of the change in solar behaviour. Thus, the next few years will give us much better estimates of the solar contribution to both global and regional climate change. For global temperature rise, there is every indication that these new estimates will, if anything, be smaller that previous estimates. On the other hand, there are indications that some regional climates will be more susceptible to solar changes (Lockwood et al. 2011a, b). Understanding spectral irradiance variability and differentiating "top-down" and "bottom-up" solar forcings will be needed as these will have very different effects on the spatial patterns of the responses and will behave differently in combination with other changes, such as sea ice loss. Key advances in this area will be made in modelling, with higher resolution in time and space, better understanding of numerical noise and of the relationship of natural climate variability to that in the model behaviour, fewer parameterisations, better definition of the inputs forcings and inclusion of more biological responses alongside the physical and chemical mechanisms.

Open Access This article is distributed under the terms of the Creative Commons Attribution License which permits any use, distribution, and reproduction in any medium, provided the original author(s) and the source are credited. 


\section{References}

Aldahan A, Hedfors J, Possnert G, Kulan A, Berggren A-M, Söderström C (2008) Atmospheric impact on beryllium isotopes as solar activity proxy. Geophys Res Lett 35:L21812. doi:10.1029/2008GL035189

Baldwin MP, Dunkerton TJ (2001) Stratospheric harbingers of anomalous weather regimes. Science 294:581-584. doi:10.1126/science.1063315

Baliunas S, Jastrow R (1990) Evidence for long-term brightness changes of solar-type stars. Nature 348:520-523. doi:10.1038/348520a0

Bard E, Raisbeck G, Yiou F, Jouzel J (1997) Solar modulation of cosmogenic nuclide production over the last millennium: comparison between ${ }^{14} \mathrm{C}$ and ${ }^{10} \mathrm{Be}$ records. Earth Planet Sci Lett 150(3/4):453-462. doi:10.1016/S0012-821X(97)00082-4

Bard E, Raisbeck G, Yiou F, Jouzel J (2000) Solar irradiance during the last 1200 years based on cosmogenic nuclides. Tellus 52B:985-992. doi:10.1034/j.1600-0889.2000.d01-7.x

Barnard L, Lockwood M, Hapgood MA, Owens MJ, Davis CJ, Steinhilber F (2011) Predicting space climate change. Geophys Res Lett 38:L16103. doi:10.1029/2011GL048489

Barriopedro D, Garcia-Herrera R, Huth R (2008) Solar modulation of Northern Hemisphere winter blocking. J Geophys Res 113:D14118. doi:10.1029/2008JD009789

Beer J (2006) Solar variability and climate change. Solar Variability Earth Clim 76:751-754

Benestad RE, Schmidt GA (2009) Solar trends and global warming. J Geophys Res 114:D14101. doi: 10.1029/2008JD011639

Berrisford P, Hoskins BJ, Tyrlis E (2007) Blocking and Rossby wave-breaking on the dynamical tropopause in the Southern Hemisphere. J Atmos Sci 64:2881-2898. doi:10.1175/JAS3984.1

Blaauw M, Heuvelink GBM, Mauquoy D, van der Plicht J, van Geel B (2003) A numerical approach to 14C wiggle-match dating of organic deposits: best fits and confidence intervals. Quat Sci Rev 22:1485-1500. doi:10.1016/S0277-3791(03)00086-6

Bochníček J, Hejda P (2005) The winter NAO pattern changes in association with solar and geomagnetic activity. J Atmos Sol-Terr Phys 67:17-32. doi: 10.1016/j.jastp.2004.07.014

Broccoli AJ et al (2003) Twentieth-century temperature and precipitation trends in ensemble climate simulations including natural and anthropogenic forcing. J Geophys Res 108(D24):4798. doi:10.1029/ 2003JD003812

Brohan P, Kennedy JJ, Haris I, Tett SFB, Jones PD (2006) Uncertainty estimates in regional and global observed temperature changes: a new dataset from 1850. J Geophys Res 111:D12106. doi:10.1029/ 2005JD006548

Brönnimann S, Ewen T, Griesser T, Jenne R (2007) Multidecadal signal of solar variability in the upper troposphere during the 20th century. Space Sci Rev 125:305-315. doi:10.1007/s11214-006-9065-2

Brown BH (2008) Short-term changes in global cloud cover and in cosmic radiation. J Atmos Sol-Terr Phys 70(7):1122-1131. doi:10.1016/j.jastp.2008.02.003

Callis LB, Natarajan M, Lambeth J (2000) Calculated upper stratospheric effects of solar UV flux and $\mathrm{NO}_{\mathrm{y}}$ variations during the 11-year solar cycle. Geophys Res Lett 27:3869-3872. doi:10.1029/2000 JD900117

Calogovic J, Albert C, Arnold F, Beer J, Desorgher L, Flueckiger EO (2010) Sudden cosmic ray decreases: no change of global cloud cover. Geophys Res Lett 37:L03802. doi:10.1029/2009GL041327

Camp CD, Tung KK (2007) Surface warming by the solar cycle as revealed by the composite mean difference projection. Geophys Res Lett 34:L14703. doi:10.1029/2007GL030207

Carslaw KS, Harrison RG, Kirkby J (2002) Cosmic rays, clouds and climate. Science 298:1732-1737. doi: 10.1126/science.1076964

Charlson RJ, Valero FPJ, Seinfeld JH (2005) In search of balance. Science 308(5723):806-807. doi: $10.1126 /$ science. 1108162

Christla M, Manginia A, Holzkäampera S, Spötlb C (2004) Evidence for a link between the flux of galactic cosmic rays and Earth's climate during the past 200000 years. J Atmos Sol-Terr Phys 66:313-322. doi:10.1016/j.jastp.2003.12.004

Coughlin K (2004) Eleven-year solar cycle signal throughout the lower atmosphere. J Geophys Res 109:D21105. doi:10.1029/2004JD004873

Courtillot V, Gallet Y, Le Mouël J-L, Fluteau F, Genevey A (2007) Are there connections between the Earth's magnetic field and climate? Earth Planet Sci Lett 253:328-339. doi:10.1016/j.epsl.2006.10.032

Cowley SWH (1991) Acceleration and heating of space plasmas-basic concepts. Annales Geophys 9(3):176-187

Cubasch U et al (1997) Simulation of the influence of solar radiation variations on the global climate with an ocean-atmosphere general circulation model. Clim Dyn 13(11):757-767. doi:10.1007/s003820050196 
Damon PE, Laut P (2004) Pattern of strange errors plagues solar activity and terrestrial climate data. EOS, Trans Am Geophys Union 85:370-374. doi:10.1029/2004EO390005

de Jager C (2008) Solar activity and its influence on climate. Netherlands J Geosci Geol Mijnbouw 87(3):207-213

de Jager C, Usoskin I (2006) On possible drivers of sun-induced climate changes. J Atmos Sol-Terr Phys 68:2053-2060. doi:10.1016/j.jastp.2006.05.019

DeLand MT, Cebula RP (2008) Creation of a composite solar ultraviolet irradiance data set. J Geophys Res 113:A11103. doi:10.1029/2008JA013401

Dickinson RE, Schaudt KJ (1998) Analysis of timescales of response of a simple climate model. J Clim 11:97-106. doi:10.1175/1520-0442(1998)011<0097:AOTORO>2.0.CO;2

Douglass DH, Clader BD (2002) Climate sensitivity of the Earth to solar irradiance. Geophys Res Lett 29(16). doi:10.1175/1520-0442(1998)011<0097:AOTORO>2.0.CO;2

Drijfhout SS, Haarsma RJ, Opsteegh JD, Selten FM (1999) Solar-induced versus internal variability in a coupled climate model. Geophys Res Lett 26:205-208. doi:10.1029/1998GL900277

Duplissy J, Enghoff MB, Aplin KL et al (2010) Results from the CERN pilot CLOUD experiment. Atmos Chem Phys 10(4):1635-1647. doi:10.5194/acp-10-1635-2010

Eddy JA (1976) The maunder minimum. Science 192(4245):1189-1202. doi:10.1126/science. 192.4245.1189

Emile-Geay J, Cane M, Seager R, Kaplan A, Allmasi P (2007) El Niño as a mediator of the solar influence on climate. Paleoceanography 22:PA3210. doi:10.1029/2006PA001304

Erlykin AD, Sloan T, Wolfendale AW (2010) Correlations of clouds, cosmic rays and solar irradiation over the Earth. J Atmos Sol-Terr Phys 72(2/3):151-156. doi:10.1016/j.jastp.2009.11.002

Feulner G, Rahmstorf S (2010) On the effect of a new grand minimum of solar activity on the future climate on Earth. Geophys Res Lett 37:L05707. doi:10.1029/2010GL042710

Field CV, Schmidt GA, Koch D, Salyk C (2006) Modeling production and climate-related impacts on Be-10 concentrations in ice cores. J Geophys Res 111:D15107. doi:10.1029/2005JD006410

Forster P, Ramaswamy V, Artaxo P, Berntsen T, Betts R, Fahey DW, Haywood J, Lean J, Lowe DC, Myhre G, Nganga J, Prinn R, Raga G, Schulz M, Van Dorland R (2007) Changes in atmospheric constituents and in radiative forcing. In: Solomon S, Qin D, Manning M, Chen Z, Marquis M, Averyt KB, Tignor M, Miller HL (eds) Climate change 2007: the physical science basis. Contribution of working group I to the fourth assessment report of the intergovernmental panel on climate change. Cambridge University Press, Cambridge

Foukal P, Fröhlich C, Spruit H, Wigley TML (2006) Variations in solar luminosity and their effect on the Earth's climate. Nature 443:161-166. doi:10.1038/nature05072

Frame T, Gray LJ (2010) The 11-year solar cycle in ERA-40 data: an update to 2008. J Clim 23:2213-2222. doi:10.1175/2009JCLI3150.1

Fröhlich C (2009) Evidence of a long-term trend in total solar irradiance. Astron Astrophys 501(3):L27L30. doi:10.1051/0004-6361/200912318

Fuller-Rowell T, Codrescu M, Maruyama N, Fredrizzi M, Araujo-Pradere E, Sazykin S, Bust G (2007) Observed and modeled thermosphere and ionosphere response to superstorms. Radio Sci 42(4): RS4S90. doi:10.1029/2005RS003392

Funke B, Lopez-Puertas M, Gil-Lopez S, von Clarmann T, Stiller G, Fischer H, Kellman S (2005) Downward transport of upper atmospheric $\mathrm{NO}_{\mathrm{x}}$ into the polar stratosphere and lower mesosphere during the Antarctic 2003 and Arctic 2002/2003 winters. J Geophys Res 110:D24308. doi: $10.1029 / 2005 J D 006463$

Gallet Y, Genevey A (2007) The Mayans: climate determinism or geomagnetic determinism? EOS Trans Am Geophys Union 88:129-130. doi:10.1029/2007E0110001

Gallet Y, Genevey A, Fluteau F (2005) Does Earth's magnetic field secular variation control centennial climate change? Earth Planet Sci Lett 236:339-347. doi:10.1016/j.eps1.2005.04.045

Gallet Y, Genevey A, Le Goff M, Fluteau F, Eshraghi SA (2006) Possible impact of the Earth's magnetic field on the history of ancient civilizations. Earth Planet Sci Lett 246:17-26. doi:10.1016/ j.eps1.2006.04.001

Giampapa M (2004), Stellar analogs of solar activity: the sun in a stellar context. In: Redi I, Güdel M, Schmutz W (eds) The sun, solar analogs and the climate. Springer, Berlin, pp 305-423, ISBN: 3-54023856-5

Gleisner H, Thejll P (2003) Patterns of tropospheric response to solar variability. Geophys Res Lett 30:17129. doi:10.1029/2003GL017129

Gleisner H, Thejll P, Stendel M, Kaas E, Machenhauer B (2005) Solar signals in tropospheric re-analysis data: comparing NCEP/NCAR and ERA40. J Atmos Sol-Terr Phys 67(8-9):785-791. doi:10.1016/ j.jastp.2005.02.001 
Gray LJ, Crooks S, Pascoe C, Sparrow S, Palmer M (2004) Solar and QBO influences on the timing of stratospheric sudden warmings. J Atmos Sci 61:2777-2796. doi:10.1175/JAS-3297.1

Gray LJ, Beer J, Geller M, Haigh J, Lockwood M, Matthes K, Cubasch U, Fleitmann D, Harrison G, Hood L, Luterbacher J, Marsh N, Shindell D, van Geel B, White W (2010) Solar influences on climate. Rev Geophys 48:RG4001. doi:10.1029/2009RG000282

Haigh JD (1994) The role of stratospheric ozone in modulating the solar radiative forcing of climate. Nature 370:544-546. doi:10.1038/370544a0

Haigh JD (2003) The effects of solar variability on the earth's climate. Philos Trans R Soc Lond A 361(95):111. doi:10.1098/rsta.2002.1111

Haigh JD (2007) The sun and the earth's climate. Living Rev Solar Phys 4:2. URL (cited on 26 September 2009): http://www.livingreviews.org/lrsp-2007-2

Haigh JD, Blackburn M (2006) Solar influences on dynamical coupling between the stratosphere and troposphere. Space Sci Rev 125:331-344. doi:10.1007/s11214-006-9067-0

Haigh JD, Winning AR, Toumi R, Harder JW (2010) An influence of solar spectral variations on radiative forcing of climate. Nature 467(7316):696-699. doi:10.1038/nature09426

Hall JC, Lockwood GW (2004) The chromospheric activity and variability of cycling and flat activity solaranalog stars. Astrophys J 614(1):942-946. doi:10.1086/423926

Hansen J, Russell G, Lacis AA, Fung I, Rind D, Stone P (1985) Climate response times: dependence on climate sensitivity and ocean mixing. Science 229:857-859. doi:10.1126/science.229.4716.857

Harder JW, Fontenla JM, Pilewskie P, Richard EC, Woods TN (2009) Trends in solar spectral irradiance variability in the visible and infrared. Geophys Res Lett 36:L07801. doi:10.1029/2008GL036797

Harrison RG (2000) Cloud formation and the possible significance of charge for atmospheric condensation and ice nuclei. Space Sci Rev 94:381-396. doi:10.1023/A:1026708415235

Harrison RG (2008) Discrimination between cosmic ray and solar irradiance effects on clouds, and evidence for geophysical modulation of cloud thickness. Proc R Soc A 464(2098):2575-2590. doi:10.1098/rspa. 2008.0081

Harrison RG, Stephenson DB (2006) Empirical evidence for a nonlinear effect of galactic cosmic rays on clouds. Proc R Soc A 462:1221-1233. doi:10.1098/rspa.2005.1628

Harrison RG, Ambaum MHP, Lockwood M (2011) Cloud base height and cosmic rays. Proc R Soc A 467:2777-2791. doi:10.1098/rspa.2011.0040

Hartley DE, Villarin JT, Black RX, Davis CA (1998) A new perspective on the dynamical link between the stratosphere and troposphere. Nature 391:471-474. doi:10.1038/35112

Haug G, Hughen K, Sigman D, Peterson L, Röhl U (2001) Southward migration of the intertropical convergence zone through the Holocene. Science 293:1304-1308. doi:10.1126/science.1059725

Hegerl GC, Zwiers FW, Braconnot P, Gillett NP, Luo Y, Marengo Orsini JA, Nicholls N, Penner JE, Stott PA (2007) Understanding and attributing climate change. In: Solomon S, Qin D, Manning M, Chen Z, Marquis M, Averyt KB, Tignor M, Miller HL (eds) Climate change 2007: the physical science basis. Contribution of working group I to the fourth assessment report of the intergovernmental panel on climate change. Cambridge University Press, Cambridge

Hegerl G, Luterbacher J, González-Rouco F, Tett SFB, Crowley T, Xoplaki E (2011) Influence of human and natural forcing on European seasonal temperatures. Nat Geosci 4:99-103. doi:10.1038/ngeo1057

Heikkila U, Beer J, Feichter J (2008) Modeling cosmogenic radionucleides Be-10 and Be-7 during the maunder minimum using the ECHAM5-HAM general circulation model. Atmos Chem Phys 8: 2797-2809. doi:10.5194/acp-8-2797-2008

Held IM, Winton M, Takahashi K, Delworth T, Zeng F, Vallis GK (2010) Probing the fast and slow components of global warming by returning abruptly to preindustrial forcing. J Clim 23(9):2418-2427. doi:10.1175/2009JCLI3466.1

Herschel W (1801) Observations tending to investigate the nature of the Sun, in order to find the causes or symptoms of its variable of light and heat; with remarks on the use that may possibly be drawn from solar observations. Philos Trans R Soc Lond 91:265-318

Huth R, Pokorná L, Bochníček J, Hejda P (2006) Solar cycle effects on modes of low-frequency circulation variability. J Geophys Res 111:D22107. doi:10.1029/2005JD006813

Huth R, Kyselý J, Bochníček J, Hejda P (2008) Solar activity affects the occurrence of synoptic types over Europe. Ann Geophys 26:1999-2004. doi:10.5194/angeo-26-1999-2008

Ineson S, Scaife AA, Knight JR, Manners JC, Dunstone NJ, Gray LJ, Haigh JD (2011) Solar forcing of winter climate variability in the northern hemisphere. Nature Geosci 4(11):753-757. doi:10.1038/ NGEO1282

Ingram WJ (2006) Detection and attribution of climate change, and understanding solar influence on climate. Space Sci Rev 125(1-4):199-211. doi:10.1007/s11214-006-9057-2 
Jackman CH, DeLand MT, Labow GJ, Fleming EI, Lopez-Puertas M (2006) Satellite measurements of middle atmospheric impacts by solar proton events in solar cycle 23. Space Sci Rev 125:381-391. doi: 10.1007/s11214-006-9071-4

Jackman CH, Marsh DR, Vitt FM, Garcia RR, Fleming EL, Labow GJ, Randall CE, Lopez-Puertas M, Funke B, von Clarmann T, Stiller GP (2008) Short- and medium-term atmospheric constituent effects of very large solar proton events. Atmos Chem Phys 8:765-785. doi:10.5194/acp-8-765-2008

Jones GS, Tett SFB, Stott PA (2003) Causes of atmospheric temperature change 1960-2000: a combined attribution analysis. Geophys Res Lett 30:1228. doi:10.1029/2002GL016377

Jones GS, Lockwood M, Stott PA (2012) What influence will future solar activity changes over the 21st century have on projected global climate changes? J Geophys Res (in press). doi:10.1029/ 2011JD017013

Karoly DJ, Stott PA (2006) Anthropogenic warming of central England temperature. Atmos Sci Lett 7:81-85. doi:10.1002/asl.136

Kazil J, Lovejoy ER, Barth MC, O’Brien K (2006) Aerosol nucleation over oceans and the role of galactic cosmic rays. Atmos Chem Phys 6:4905-4924. doi:10.5194/acp-6-4905-2006

Kernthaler SC, Toumi R, Haigh JD (1999) Some doubts concerning a link between cosmic ray fluxes and global cloudiness. Geophys Res Lett 26(7):863-865. doi:10.1029/1999GL900121

Kilian MR, van der Plicht J, van Geel B (1995) Dating raised bogs: new aspects of AMS ${ }^{14} \mathrm{C}$ wiggle matching, a reservoir effect and climatic change. Quat Sci Rev 14:959-966. doi: 10.1016/0277-3791(95)00081-X

Kirkby J (2007) Cosmic rays and climate. Surv Geophys 28(5/6):333-375. doi:10.1007/s10712-008-9030-6

Kirkby J, Curtius J, Almeida J et al (2011) Role of sulphuric acid, ammonia and galactic cosmic rays in atmospheric aerosol nucleation. Nature 476(7361):429-433. doi:10.1038/nature10343

Klein SA, Hartmann DL (1993) Spurious changes in the ISCCP dataset. Geophys Res Lett 20:455-458. doi: 10.1029/93GL00211

Knutti R, Krähenmann S, Frame DJ, Allen MR (2008) Comment on “Heat capacity, time constant, and sensitivity of Earth's climate system"' by S. E. Schwartz. J Geophys Res 113:D15103. doi:10.1029/ 2007JD009473

Kodera K (2002) Solar cycle modulation of the North Atlantic Oscillation: implications in the spatial structure of the NAO. Geophys Res Lett 29(8):1218. doi:10.1029/2001GL014557

Kodera K, Kuroda Y (2005) A possible mechanism of solar modulation of the spatial structure of the North Atlantic Oscillation. J Geophys Res 110:D02111. doi:10.1029/2004JD005258

Kossobokov V, Le Mouël J-L, Courtillot V (2010) A statistically significant signature of multidecadal solar activity changes in atmospheric temperatures at three European stations. J Atmos Sol-Terr Phys 72:595-606. doi:10.1016/j.jastp.2010.02.016

Kristjánsson JE, Kristiansen J (2000) Is there a cosmic ray signal in recent variations in global cloudiness and cloud radiative forcing? J Geophys Res 105(D9):11851-11863. doi:10.1029/2000JD900029

Kristjánsson JE, Stjern CW, Stordal F et al (2008) Cosmic rays, cloud condensation nuclei and clouds-a reassessment using MODIS data. Atmos Chem Phys 8(24):7373-7387. doi:10.5194/acp-8-7373-2008

Krivova NA, Solanki SK, Wenzler T, Podlipnik B (2009) Reconstruction of solar UV irradiance since 1974. J Geophys Res 114:D00I04. doi:10.1029/2009JD012375

Krivova NA, Solanki SK, Unruh YC (2011) Towards a long-term record of solar total and spectral irradiance. J Atmos Sol-Terr Phys 73:223-234. doi:10.1016/j.jastp.2009.11.013

Kulmala M, Riipinen I, Nieminen T, Hulkkonen M, Sogacheva L, Manninen HE, Paasonen P, Petäjä T, Dal Maso M, Aalto PP, Viljanen A, Usoskin I, Vainio R, Mirme S, Mirme A, Minikin A, Petzold A, Hõrrak U, Plaß-Dülmer C, Birmili W, Kerminen V-M (2010) Atmospheric data over a solar cycle: no connection between galactic cosmic rays and new particle formation. Atmos Chem Phys 10:1885-1898. doi:10.5194/acp-10-1885-2010

Kushner PJ, Polvani LM (2004) Stratosphere-troposphere coupling in a relatively simple AGCM: the role of eddies. J Clim 17:629-639. doi:10.1175/1520-0442(2004)017<0629:SCIARS >2.0.CO;2

Laken B, Wolfendale A, Kniveton D (2009) Cosmic ray decreases and changes in the liquid water cloud fraction over the oceans. Geophys Res Lett 36:L23803. doi:10.1029/2009GL040961

Le Mouël J-L, Courtillot V, Blanter E, Shnirman M (2008) Evidence for a solar signature in 20th-century temperature data from the USA and Europe. C R Geosci 340:421-430. doi:10.1016/j.crte.2008.06.001

Le Mouël J-L, Blanter E, Shnirman M, Courtillot V (2009) Evidence for solar forcing in variability of temperature and pressure in Europe. J Atmos Solar-Terr Phys 71:1309-1321. doi:10.1016/ j.jastp.2009.05.006

Le Mouël J-L, Kossobokov V, Courtillot V (2010) A solar pattern in the longest temperature series from three stations in Europe. J Atmos Sol-Terr Phys 72:62-76. doi:10.1016/j.jastp.2009.10.009 
Le H, Liu L, He H, Wan W (2011) Statistical analysis of solar EUV and X-ray flux enhancements induced by solar flares and its implication to upper atmosphere. J Geophys Res 116:A11301. doi: 10.1029/2011JA016704

Lean J (2000) Evolution of the Sun's spectral irradiance since the Maunder Minimum. Geophys Res Lett 27:2425-2428. doi:10.1029/2000GL000043

Lean J (2006) Comment on "Estimated solar contribution to the global surface warming using the ACRIM TSI satellite composite" by N. Scafetta and B. J. West (2006). Geophys Res Lett 33:L15701. doi: $10.1029 / 2005$ GL025342

Lean J (2010) Cycles and trends in solar irradiance and climate. Wiley Interdiscip Rev Clim Change 1(1):111-122. doi:10.1002/wcc.018

Lean JL, Rind DH (2008) How natural and anthropogenic influences alter global and regional surface temperatures: 1889 to 2006. Geophys Res Lett 35:L1870. doi:10.1029/2008GL034864

Lean JL, Rind DH (2009) How will Earth's surface temperature change in future decades? Geophys Res Lett 36:L15708. doi:10.1029/2009GL038932

Lean JL, Rottman GJ, Kyle HL, Woods TN, Hickey JR, Puga LC (1997) Detection and parameterization of variations in solar midand near-ultraviolet radiation (200-400 nm). J Geophys Res 102(29):939. doi: 10.1029/97JD02092

Legras B, Mestre O, Bard E, Yiou P (2010) On misleading solar-climate relationship. Clim Past Discuss 6:767-800. doi:10.5194/cpd-6-767-2010

Lockwood M (2002) An evaluation of the correlation between open solar flux and total solar irradiance. Astron Astrophys 382:678-687. doi:10.1051/0004-6361:20011666

Lockwood M (2004) Solar Outputs, their variations and their effects of Earth. In: Haigh JD, Lockwood M, Giampapa MS, Rüedi I, Güdel M, Schmutz W (eds) The sun, solar analogs and the climate. Proceedings of Saas-Fee advanced course. Springer, Berlin, vol 34, pp 107-304, ISBN: 3-540-23856-5

Lockwood M (2006) What do cosmogenic isotopes tell us about past solar forcing of climate? Space Sci Rev 125:95-109. doi:10.1007/s11214-006-9049-2

Lockwood M (2008) Recent changes in solar outputs and the global mean surface temperature. III. Analysis of contributions to global mean air surface temperature rise. Proc R Soc A 464(2094):1387-1404. doi: 10.1098/rspa.2007.0348

Lockwood M (2010) Solar change and climate: an update in the light of the current exceptional solar minimum. Proc R Soc A 466(2114):303-329. doi:10.1098/rspa.2009.0519

Lockwood M (2011a) Was UV spectral solar irradiance lower during the recent low sunspot minimum? J Geophys Res 116:D16103. doi:10.1029/2010JD014746

Lockwood M (2011b) Solar physics: shining a light on solar impacts. Nat Clim Change 1:98-99. doi: 10.1038 /nclimate 1096

Lockwood M (2012) Solar induced climate effects. In: Robert M (ed) Encyclopaedia of sustainability science and technology. Springer, Berlin, ISBN 978-0-387-89469-0

Lockwood M, Fröhlich C (2007) Recent oppositely-directed trends in solar climate forcings and the global mean surface air temperature. Proc R Soc (Lond) A 463(2086):2447-2460. doi:10.1098/rspa2007.1880

Lockwood M, Fröhlich C (2008) Recent oppositely-directed trends in solar climate forcings and the global mean surface air temperature: II. Different reconstructions of the total solar irradiance variation and dependence on response timescale. Proc R Soc (Lond) 464(2094):1367-1385. doi:10.1098/rspa. 2007.0347

Lockwood M, Owens MJ (2011) Centennial changes in the heliospheric magnetic field and open solar flux: the consensus view from geomagnetic data and cosmogenic isotopes and its implications. J Geophys Res 116:A04109. doi:10.1029/2010JA016220

Lockwood M, Stamper R (1999) Long-term drift of the coronal source magnetic flux and the total solar irradiance. Geophys Res Lett 26:2461-2464. doi:10.1029/1999GL900485

Lockwood M, Rouillard AP, Finch ID (2009) The rise and fall of open solar flux during the current grand solar maximum. Appl J 700:937-944. doi:10.1088/0004-637X/700/2/937

Lockwood M, Harrison RG, Woollings T, Solanki SK (2010a) Are cold winters in Europe associated with low solar activity? Environ Res Lett 5:024001. doi:10.1088/1748-9326/5/2/024001

Lockwood M, Bell C, Woollings T, Harrison RG, Gray LJ, Haigh JD (2010b) Top-down solar modulation of climate: evidence for centennial-scale change. Environ Res Lett 5:034008. doi:10.1088/ $1748-9326 / 5 / 3 / 034008$

Lockwood M, Harrison RG, Owens MJ, Barnard L, Woollings T, Steinhilber F (2011a) The solar influence on the probability of relatively cold UK winters in the future. Environ Res Lett 6:034004. doi: $10.1088 / 1748-9326 / 6 / 3 / 034004$ 
Lockwood M, Owens MJ, Barnard L, Davis CJ, Steinhilber F (2011b) The persistence of solar activity indicators and the descent of the sun into maunder minimum conditions. Geophys Res Lett 38:L22105. doi:10.1029/2011GL049811

Loeb NG, Wielicki BA, Doelling DR, Kato S, Wong T, Smith GL, Keyes DF, Manalo-Smith N (2009) Toward optimal closure of the earth's top-of-atmosphere radiation budget. J Clim 22(3):748-766. doi: 10.1175/2008JCLI2637

Loukitcheva MA, Solanki SK, White SM (2009) The relationship between chromospheric emissions and magnetic field strength. Astron Astrophys 497(1):273-285. doi:10.1051/0004-6361/200811133

Love JJ, Mursula K, Tsai VC, Perkins DM (2011) Are secular correlations between sunspots, geomagnetic activity, and global temperature significant? Geophys Res Lett 38:L21703. doi: $10.1029 / 2011$ GL049380

Lu H, Jarvis MJ, Hibbins RE (2008) Possible solar wind effect on the northern annular mode and northern hemispheric circulation during winter and spring. J Geophys Res 113:D23104. doi: 10.1029/2008JD010848

Luterbacher J et al (2001) The late maunder minimum (1675-1715) - a key period for studying decadal scale climatic change in Europe. Clim Change 49:441-462. doi:10.1023/A:1010667524422

Manley G (1974) Central England temperatures: monthly means 1659 to 1973. Q J R Meteorol Soc 100:389-405. doi:10.1256/smsqj.42510

Mann ME, Zhang ZH, Rutherford S, Bradley RS, Hughes MK, Shindell D, Ammann C, Faluvegi G, Ni FB (2009) Global signatures and dynamical origins of the little ice age and medieval climate anomaly. Science 326(5957):1256-1260. doi:10.1126/science.1177303

Marsch E (2006) Solar wind responses to the solar activity cycle. Adv Space Res 38(5):921-930. doi: 10.1016/j.asr.2005.07.029

Marsh N, Svensmark H (2000) Cosmic rays, clouds, and climate. Space Sci Rev 94:215-230. doi: 10.1023/A:1026723423896

Marsh N, Svensmark H (2003), Galactic cosmic ray and El Nino Southern Oscillation trends in international satellite cloud climatology project D2 low-cloud properties. J Geophys Res 108(D6):4195. doi: 10.1029/2001JD001264

Marsh N, Svensmark H (2004) Comment on 'Solar influences on cosmic rays and cloud formation: a reassessment' by Bomin Sun and Raymond S. Bradley. J Geophys Res 109:D14205. doi:10.1029/ 2003JD004063

Matthes K, Kuroda Y, Kodera K, Langematz U (2006) Transfer of the solar signal from the stratosphere to the troposphere: Northern winter. J Geophys Res 111:D06108. doi:10.1029/2005JD006283

McCracken KG, Beer J (2007) Long-term changes in the cosmic ray intensity at Earth, 1428-2005. J Geophys Res 112:A10101. doi:10.1029/2006JA012117

Meehl GA, Washington WM, Wigley TML, Arblaster JM, Dai A (2003) Solar and greenhouse gas forcing and climate response in the twentieth century. J Clim 16:426-444. doi:10.1175/15200442

Meehl GA et al (2004) Combinations of natural and anthropogenic forcings in 20th century climate. J Clim 17:3721-3727. doi:10.1175/1520-0442(2004)017<3721:CONAAF $>2.0$. CO;2

Meehl GA, Arblaster JM, Branstator G, van Loon H (2008) A coupled air-sea response mechanism to solar forcing in the Pacific region. J Clim 21:2883-2897. doi:10.1175/2007JCLI1776.1

Meehl GA, Arblaster JM, Matthes K, Sassi F, van Loon H (2009) Amplifying the Pacific climate system response to a small 11-year solar cycle forcing. Science 325:1114-1118. doi:10.1126/science.1172872

Mlynczak M et al (2003) The natural thermostat of nitric oxide emission at $5.3 \mu \mathrm{m}$ in the thermosphere observed during the solar storms of, April 2002. Geophys Res Lett 30:2100. doi:10.1029/ 2003GL017693

Moore J, Grinsted A, Jevrejeva S (2006) Is there evidence for sunspot forcing of climate at multi-year and decadal periods? Geophys Res Lett 33:L17705. doi:10.1029/2006GL026501

Muscheler R, Joos F, Beer J, Muller SA, Vonmoos M, Snowball I (2007) Solar activity during the last $1000 \mathrm{yr}$ inferred from radionucleide records. Quat Sci Rev 26:82-97. doi:10.1016/ j.quascirev.2006.07.012

Ney EP (1959) Cosmic radiation and the weather. Nature 183:451-452. doi:10.1038/183451a0

Nöel M, Tarling DH (1975) The Laschamp geomagnetic 'event'. Nature 253:705-707. doi:10.1038/ $253705 \mathrm{a} 0$

North GR, Stevens MJ (1998) Detecting climate signals in the surface temperature record. J Clim 11:563-577. doi:10.1175/1520-0442(1998)011<0563:DCSITS >2.0.CO;2

Owens MJ, Lockwood M, Barnard L, Davis CJ (2011) Solar cycle 24: implications for energetic particles and the probability of a new Maunder Minimum. Geophys Res Lett 38:L19106. doi:10.1029/ 2011GL049328 
Pallé E, Goode PR, Montañés-Rodriguez P (2009) Interannual variations in Earth's reflectance 1999-2007. J Geophys Res 114:D00D03. doi:10.1029/2008JD010734

Parker DE, Legg TP, Folland CK (1992) A new daily Central England temperature series, 1772-1991. Int J Clim 12:317-342. doi:10.1002/joc.3370120402

Perlwitz J, Harnik N (2003) Observational evidence of a stratospheric influence on the troposphere by planetary wave reflection. J Clim 16:3011-3026. doi:10.1175/1520-0442(2003)016<3011:OEOASI > 2.0.CO;2

Pierce JR, Adams PJ (2009) Can cosmic rays affect cloud condensation nuclei by altering new particle formation rates? Geophys Res Lett 36:L09820. doi:10.1029/2009GL037946

Plumb RA, Semeniuk K (2003) Downward propagation of extra-tropical zonal wind anomalies. J Geophys Res 108. doi:10.1029/2002JD002773

Poore RZ, Quinn TM, Verardo S (2004) Century-scale movement of the Atlantic intertropical convergence zone linked to solar variability. Geophys Res Lett 31:L12214. doi:10.1029/2004GL019940

Potgieter MS (2008) The modulation of galactic cosmic rays in the heliosphere: theory and models. Space Sci Rev 83(1-2):147-158. doi:10.1023/A:1005014722123

Qu WZ, Huang F, Du L, Zhao JP, Qin T, Cao Y (2011) The periodicity of volcano activity and its reflection in some climate factors. Chin J Geophys Chin Edn 54(3):643-655. doi:10.3969/j.issn. 0001-5733.2011.03.003

Randall CE, Harvey VL, Manney GL, Orsolini Y, Codrescu M, Sioris C, Brohede S, Haley C, Gordley L, Zawodny J, Russell J III (2005) Stratospheric effects of energetic particle precipitation in 2003-2004. Geophys Res Lett 32:L05802. doi:10.1029/2004GL022003

Randall CE, Harvey V, Singleton CS, Bailey S, Bernath P, Codrescu M, Nakajima H, Russell JM III (2007) Energetic particle precipitation effects on the Southern Hemisphere stratosphere in 1992-2005. J Geophys Res 112:D08308. doi:10.1029/2006JD007696

Reid G (2000) Solar variability and the Earth's climate: introduction and overview. Space Sci Rev 94:1-11. doi:10.1023/A:1026797127105

Rind D (2002) The Sun's role in climate variations. Science 296:673-678. doi:10.1126/science.1069562

Rind D, Lean J, Healy R (1999) Simulated time-dependent climate response to solar radiative forcing since 1600. J Geophys Res 104:1973-1990. doi:10.1029/1998JD200020

Rind D, Lean J, Lerner J, Lonergan P, Leboissitier A (2008) Exploring the stratospheric/tropospheric response to solar forcing. J Geophys Res Atmos 113:D24103. doi:10.1029/2008JD010114

Rouillard AP, Lockwood M (2004) Oscillations in the open solar magnetic flux with period 1.68 years: imprint on galactic cosmic rays and implications for heliospheric shielding. Ann Geophys 22: 4381-4396. doi:10.5194/angeo-22-4381-2004

Rozanov EV, Callis L, Schlesinger E, Yang F, Andronova N, Zubov VA (2005) Atmospheric response to NOy source due to energetic electron precipitation. J Geophys Res 32:L14811. doi: 10.1029/2005GL023041

Rozanov E, Calisto M, Egorova T, Peter T, Schmutz W (2012) The influence of the precipitating energetic particles on atmospheric chemistry and climate. Surv Geophys. doi:10.1007/s10712-012-9192-0

Ruzmaikin A, Feynman J (2002) Solar influence on a major mode of atmospheric variability. J Geophys Res 107:4209. doi:10.1029/2001JD001239

Rycroft MJ, Harrison RG, Nicoll KA, Mareev EA (2008) An overview of earth's global electric circuit and atmospheric conductivity. Space Sci Rev 137(1-4):83-105. doi:10.1007/s11214-008-9368-6

Santer BD, Wigley TML, Doutriaux C, Boyle JS, Hansen JE, Jones PD, Meehl GA, Roeckner E, Sengupta $S$, Taylor KE (2001) Accounting for the effects of volcanoes and ENSO in comparisons of modelled and observed temperature trends. J Geophys Res 106:28033-28059. doi:10.1029/2000JD000189

Scafetta N (2009) Empirical analysis of the solar contribution to global mean air surface temperature change. J Atmos Sol Terr Phys 71(17-18):1916-1923. doi:10.1016/j.jastp.2009.07.007

Scafetta N, West BJ (2007) Phenomenological reconstructions of the solar signature in the Northern Hemisphere surface temperature records since 1600. J Geophys Res 112(D24):D24S03. doi:10.1029/ 2007JD008437

Scaife AA, Knight JR, Vallis GK, Folland CK (2005) A stratospheric influence on the winter NAO and North Atlantic surface climate. Geophys Res Lett 32:L18715. doi:10.1029/2005GL023226

Schmidt GA, Jungclaus JH, Ammann CM, Bard E, Braconnot P, Crowley TJ, Delaygue G, Joos F, Krivova NA, Muscheler R, Otto-Bliesner BL, Pongratz J, Shindell DT, Solanki SK, Steinhilber F, Vieira LEA (2011) Climate forcing reconstructions for use in PMIP simulations of the Last Millennium (v1.1). Geosci Model Dev Discuss 4:2451-2467, www.geosci-model-dev-discuss.net/4/2451/2011/. doi: 10.5194/gmdd-4-2451-2011 
Schrijver CJ, Livingston WC, Woods TN, Mewaldt RA (2011) The minimal solar activity in 2008-2009 and its implications for long-term climate modeling. Geophys Res Lett 38:L06701. doi: 10.1029/2011GL046658

Schwenn R (2006) Space weather: the solar perspective. Living Rev Solar Phys 3(2). URL (cited on 17/1/ 2012): http://www.livingreviews.org/lrsp-2006-2

Seppälä A, Randall CE, Clilverd MA, Rozanov E, Rodger CJ (2009) Geomagnetic activity and polar surface air temperature variability. J Geophys Res 114:A10312. doi:10.1029/2008JA014029

Shapiro AI, Schmutz W, Rozanov E, Schoell M, Harberreiter M, Shapiro AV, Nyeki S (2011) A new approach to the long-term reconstruction of the solar irradiance leads to large historical solar forcing. Astron \& Astrophys 529:A67. doi:10.1051/0004-6361/201016173

Shepherd TG (2002) Issues in stratosphere-troposphere coupling. J Met Soc Jpn 80:769-792. doi: $10.2151 /$ jmsj.80.769

Shindell DT, Schmidt GA, Miller RL, Rind D (2001a) Northern hemisphere winter climate response to greenhouse gas, ozone, solar, and volcanic forcing. J Geophys Res 106:7193-7210. doi: 10.1029/2000JD900547

Shindell DT, Schmidt GA, Mann ME, Rind D, Waple A (2001b) Solar forcing of regional climate change during the maunder minimum. Science 294(5549):2149-2152. doi:10.1126/science.1064363

Shine KP, Fouquart Y, Ramaswamy V, Solomon S, Srinivasan J (1995) Radiative forcing. In: Houghton JT et al (eds) Climate change 1994. Cambridge University Press, Cambridge, Chapter 4, pp 163-203, ISBN 0521550556

Simpson IR, Blackburn M, Haigh JD (2009) The role of eddies in driving the tropospheric response to stratospheric heating perturbations. J Atmos Sci 66(5):1347-1365. doi:10.1175/2008JAS2758.1

Siskind DE, Nedoluha GE, Randall CE, Fromm M, Russell JM III (2000) An assessment of Southern Hemisphere stratospheric NOx enhancements due to transport from the upper atmosphere. Geophys Res Lett 27:329-332. doi:10.1029/1999GL010940

Sloan T, Wolfendale AW (2008) Testing the proposed causal link between cosmic rays and cloud cover. Environ Res Lett 3(2):024001. doi:10.1088/1748-9326/3/2/024001

Slonosky VC, Jones PD, Davies TD (2001) Instrumental pressure observations and atmospheric circulation from the 17th and 18th centuries. Lond Paris Int J Climatol 21:285-298. doi:10.1002/joc.611

Solanki SK, Krivova NA, Wenzler T (2005) Irradiance models. Adv Sp Res 35:376-383. doi: 10.1016/j.asr.2004.12.077

Song YC, Robinson WA (2004) Dynamical mechanisms for stratospheric influences on the troposphere. J Atmos Sci 61:1711-1725. doi:10.1175/1520-0469(2004)061<1711:DMFSIO>2.0.CO;2

Steinhilber F, Abreu JA, Beer J (2008) Solar modulation during the Holocene. Astrophys Space Sci Trans 4(1-6):2008. doi:10.5194/astra-4-1-2008

Steinhilber F, Beer J, Fröhlich C (2009) Total solar irradiance during the Holocene. Geophys Res Lett 36:L19704. doi:10.1029/2009GL040142

Stendel M, Mogensen IA, Christensen JH (2006) Influence of various forcings on global climate in historical times using a coupled atmosphere-ocean general circulation model. Clim Dyn 26(1):1-15. doi: 10.1007/s00382-005-0041-4

Stone DA, Allen MR, Stott PA (2007a) A multi-model update on the detection and attribution of global surface warming. J Clim 20:517-530. doi:10.1175/JCLI3964.1

Stone DA, Allen MR, Selten F, Kilphuis M (2007b) The detection and attribution of climate change using an ensemble of opportunity. J Clim 20:504-516. doi:10.1175/JCLI3966.1

Stott PA, Jones GS (2009) Variability of high latitude amplification of anthropogenic warming. Geophys Res Lett 36:L10701. doi:10.1029/2009GL037698

Stott PA, Tett SFB, Jones GS, Allen MR, Mitchell JFB, Jenkin GJ (2000) External control of 20th century temperature by natural and anthropogenic forcings. Science 290(5499):2133-2137. doi: $10.1126 /$ science. 290.5499 .2133

Stott PA, Jones GS, Mitchell JF (2003) Do models underestimate the solar contribution to recent climate change? J Clim 16:4079-4093. doi:10.1175/1520-0442(2003)016<4079:DMUTSC >2.0.CO;2

Sun B, Bradley RS (2002) Solar influences on cosmic rays and cloud formation: a reassessment. J Geophys Res 107(D14):4211. doi:10.1029/2001JD000560

Sun B, Bradley RS (2004) Reply to comment by N. D. Marsh and H. Svensmark on "Solar influences on cosmic rays and cloud formation: a reassessment". J Geophys Res 109:D14206. doi: 10.1029/2003JD004479

Svensmark H (2007) Cosmoclimatology: a new theory emerges. Astron Geophys 48:118-124. doi: 10.1111/j.1468-4004.2007.48118.x 
Svensmark H, Friis-Christensen E (1997) Variations of cosmic ray flux and global cloud coverage-a missing link in solar-climate relationships. J Atmos Terr Phys 59:1225-1232. doi:10.1016/S13646826(97)00001-1

Svensmark H, Bondo T, Svensmark J (2009) Cosmic rays decreases affect atmospheric aerosols and cloud. Geophys Res Lett 36:L15101. doi:10.1029/2009GL038429

Tett SFB et al (2002) Estimation of natural and anthropogenic contributions to twentieth century temperature change. J Geophys Res 107(D16):4306. doi:10.1029/2000JD000028

Tett SFB et al (1999) Causes of twentieth-century temperature change near the Earth's surface. Nature 399:569-572. doi:10.1038/21164

Thayer JP, Semeter J (2004) The convergence of magnetospheric energy flux in the polar atmosphere. J Atmos Sol-Terr Phys 66(10):807-824. doi:10.1016/j.jastp.2004.01.035

Thejll P, Christiansen B, Gleisner H (2003) On correlations between the North Atlantic Oscillation, geopotential heights and geomagnetic activity. Geophys Res Lett 30(6):1347. doi:10.1029/2002GL016598

Udelhofen PM, Cess RD (2001) Cloud cover variations over the united states: an influence of cosmic rays or solar variability? Geophys Res Lett 28(13):2617-2620. doi:10.1029/2000GL012659

Uppala SM et al (2005) The ERA-40 re-analysis. Q J R Meteorol Soc 131(612):2961-3012. doi:10.1256/ qj.04.176

van Geel B, Mook WG (1989) High resolution 14C dating of organic deposits using natural atmospheric 14C variations. Radiocarbon 31:151-155

Veretenenko VS, Pudovkin MI (1997) Effects of the galactic cosmic ray variations on the solar radiation input in the lower atmosphere. J Atmos Terr Phys 59(14):1739-1746. doi:10.1016/S1364-6826 (96)00183-6

Vieira LEA, Solanki SK, Krivova NA, Usoskin I (2011) Evolution of the solar irradiance during the Holocene. Astron Astrophys 531:A6. doi:10.1051/0004-6361/201015843

Voiculescu M, Usoskin IG, Mursula K (2006) Different response of clouds to solar input. Geophys Res Lett 33:L21802. doi:10.1029/2006GL027820

Vonmoos M, Beer J, Muscheler R (2006) Large variations in Holocene solar activity: constraints from Be10 in the Greenland Ice core project ice core. J Geophys Res 111:A10105. doi:10.1029/2005JA011500

Wagner G, Lvingstone DM, Masarik J, Muscheler R, Beer J (2001) Some results relevant to the discussion of a possible link between cosmic rays and the Earth's climate. J Geophys Res 106(D4):3381-3387. doi:10.1029/2000JD900589

Wang Y-M, Lean JL, Sheeley NR Jr (2005) Modeling the Sun's magnetic field and irradiance since 1713. Appl J 625:522-538. doi:10.1086/429689

Wanner H, Pfister C, Brázdil R, Frich P, Frydendahl K, Jónsson T, Kington J, Lamb HH, Rosenørn S, Wishman E (1995) Wintertime European circulation patterns during the late Maunder Minimum cooling period (1675-1704). Theor Appl Clim 51:167-175. doi:10.1007/BF00867443

Waple AM, Mann ME, Bradley RS (2002) Long-term patterns of solar irradiance forcing in model experiments and proxy-based surface temperature reconstructions. Clim Dyn 18:563-578. doi: 10.1007/s00382-001-0199-3

Weber SL (2005) A timescale analysis of the Northern Hemisphere temperature response to volcanic and solar forcing. Clim Past 1:9-17. doi:10.5194/cp-1-9-2005

Weiss NO, Thompson MJ (2009) The solar dynamo. Space Sci Rev 144(1-4):53-66. doi:10.1007/ s11214-008-9435-Z

Wenzler T, Solanki SK, Kirova NA, Fröhlich C (2006) Reconstruction of solar irradiance variations in cycles 21-23 based on surface magnetic fields. A\&A 460:583-595. doi:10.1051/0004-6361:20065752

White WB, Liu Z (2008a) Non-linear alignment of El Niño to the 11-yr solar cycle. Geophys Res Lett 35:L19607. doi:10.1029/2008GL034831

White WB, Liu Z (2008b) Resonant response of the quasi-decadal oscillation to the 11-yr period signal in the Sun's irradiance. J Geophys Res 113:C01002. doi:10.1029/2006JC004057

White WB, Lean J, Cayan DR, Dettinger MD (1997) Response of global upper ocean temperature to changing solar irradiance. J Geophys Res 102(C2):3255-3266. doi:10.1029/96JC03549

Wigley TML, Raper SCB (1990) Climatic change due to solar irradiance changes. Geophys Res Lett 17:2169-2172. doi:10.1029/GL017i012p02169

Woollings T, Charlton-Perez A, Ineson S, Marshall AG, Masato G (2010a) Associations between stratospheric variability and tropospheric blocking. J Geophys Res 115:D06108. doi:10.1029/2009JD012742

Woollings T, Lockwood M, Masato G, Bell C, Gray L (2010b) Enhanced signature of solar variability in Eurasian winter climate. Geophys Res Lett 37:L20805. doi:10.1029/2010GL044601

Yiou P, Bard E, Dandin P, Legras B, Naveau P, Rust HW, Terray L, Vrac M (2010) Statistical issues about solar-climate relations. Clim Past Discuss 6:461-487. http://www.clim-past-discuss.net/6/461/2010/ 
Zhang Q, Soon WH, Baliunas SL, Lockwood GW, Skiff BA, Raddick RR (1994) A method of determining possible brightness variations of the Sun in past centuries from observations of solar-type stars. Astrophys J 427:L111-L114. doi:10.1086/187377

Zorita E, von Storch H, Gonzalez-Rouco F, Cubasch U, Luterbacher J, Legutke S, Fischer-Bruns I, Schlese U (2004) Climate evolution in the last five centuries simulated by an atmosphere-ocean model: global temperatures, the North Atlantic Oscillation and the Late Maunder Minimum. Meteor Zeit 13:271-289. doi:10.1127/0941-2984/2004/0013-0271 